\title{
Optimized medium via statistical approach enhanced threonine production by Pediococcus pentosaceus TL-3 isolated from Malaysian food
}

\author{
Ye Heng Lim ${ }^{1}$, Hooi Ling Foo ${ }^{1,2^{*}}$, Teck Chwen Loh ${ }^{3,4^{*}}$, Rosfarizan Mohamad ${ }^{2,5}$, Raha Abdul Rahim ${ }^{1,6}$ \\ and Zulkifli ldrus 3,4,7
}

\begin{abstract}
Background: Threonine is an essential amino acid that is extensively used in livestock industry as feed supplement due to its pronounced effect in improving the growth performance of animals. Application of genetically engineered bacteria for amino acid production has its share of controversies after eosinophils myalgia syndrome outbreak in 1980s. This has urged for continuous search for a food grade producer as a safer alternative for industrial amino acid production. Lactic acid bacteria (LAB) appear as an exceptional candidate owing to their non-pathogenic nature and reputation of Generally Recognized as Safe (GRAS) status. Recently, we have identified a LAB, Pediococcus pentosaceus $T L-3$, isolated from Malaysian food as a potential threonine producer. Thus, the objective of this study was to enhance the threonine production by P. pentosaceus TL-3 via optimized medium developed by using Plackett-Burman design (PBD) and central composite design (CCD).
\end{abstract}

Results: Molasses, meat extract, $\left(\mathrm{NH}_{4}\right)_{2} \mathrm{SO}_{4}$, and $\mathrm{MnSO}_{4}$ were identified as the main medium components for threonine production by P. pentosaceus TL-3. The optimum concentration of molasses, meat extract, $\left(\mathrm{NH}_{4}\right)_{2} \mathrm{SO}_{4}$ and $\mathrm{MnSO}_{4}$ were found to be $30.79 \mathrm{~g} / \mathrm{L}, 25.30 \mathrm{~g} / \mathrm{L}, 8.59 \mathrm{~g} / \mathrm{L}$, and $0.098 \mathrm{~g} / \mathrm{L}$ respectively based on model obtained in CCD with a predicted net threonine production of $123.07 \mathrm{mg} / \mathrm{L}$. The net threonine production by P. pentosaceus TL-3 in the optimized medium was enhanced approximately 2 folds compared to the control.

Conclusions: This study has revealed the potential of P. pentosaceus TL-3 as a safer alternative to produce threonine. Additionally, the current study has identified the key medium components affecting the production of threonine by P. pentosaceus TL-3, followed by optimization of their concentrations by means of statistical approach. The findings of this study could act as a guideline for the future exploration of amino acid production by LAB.

Keywords: Central composite design, Pediococcus pentosaceus TL-3, Plackett-Burman design, Statistical optimization, Threonine production

\section{Background}

Threonine is an essential amino acid that is used extensively in livestock industry as feed supplement due to its pronounced effect in improving the growth performance of animals [1]. It is the third limiting amino acid

\footnotetext{
*Correspondence: hlfoo@upm.edu.my; tcloh@upm.edu.my

${ }^{1}$ Institute of Bioscience, Universiti Putra Malaysia, 43400 UPM Serdang,

Selangor, Malaysia

${ }^{3}$ Department of Animal Science, Faculty of Agriculture, Universiti Putra

Malaysia, 43400 UPM Serdang, Selangor, Malaysia

Full list of author information is available at the end of the article
}

for poultry, after lysine and methionine. Threonine was deemed to play a vital role in maintenance of the proper gut function and essential for mucin synthesis [2]. Apart from that, supplementation of threonine was found effective in improving the breast meat deposition in broiler [3], as well as enhancing the intestinal morphology and growth performance of pigs [4] and starter Pekin ducks [5].

Currently, threonine production relies heavily on fermentation method by using modified strains of Corynebacterium glutamicum [6] and Escherichia coli [7]. 
However, pathogenicity of these microorganisms could raise concern for the consumers, whereby utilization of genetically engineered bacteria for amino acid production has its share of controversies particularly after the eosinophils myalgia syndrome (EMS) outbreak in 1980s attributed to the toxin produced by an engineered bacterium [8]. This has urged for continuous search of a safer alternative food grade amino acid producer. Lactic acid bacteria (LAB) appear as an exceptional candidate owing to their non-pathogenic nature and reputation as Generally Recognized as Safe (GRAS) microorganism [9]. Moreover, numerous studies have reported that LAB possess capability to produce various amino acids [1018]. Nevertheless, there were limited documentation on the application of LAB for amino acid production.

Process optimization is an important step in industrial production processes to ensure higher productivity at minimal cost. Improvement of microbial metabolites production in a fermentation process is often achieved by manipulating the physical and nutritional parameters or via strain improvement. Optimization of nutritional parameter is one of the most prevalent approach due to its effectiveness [19]. Optimization of medium formulation can be accomplished by using either conventional or statistical method or combination of both. Conventional method involves varying an independent variable at a time while keeping the other variables constant. This is often laborious and time consuming especially when a huge number of variables are involved. In contrast, statistical method is rapid, more reliable and cost effective as it reduces the number of experimental runs tremendously $[20,21]$.

Dozens of designs are available in the statistical method and the choice is often dependent on the objectives of the experiment. Generally, they can be categorized into 3 main types, which are screening, factorial, and response surface methodology. Screening designs are also referred as Resolution III designs, which are commonly employed to scout the experimental space when the understanding on the system is limited. Plackett-Burman design (PBD) is an example of screening design, which is useful to elucidate the main effect of each variable [22]. It involves $4 n$ experiments and the maximum number of variables that can be studied is $4 n-1$, where a PBD with 12 experimental runs can handle up to 11 variables [23]. Meanwhile, central composite design (CCD) is one of the most commonly employed Response Surface Methodology. It comprises of three distinct parts including a factorial portion, a center point portion and an axial portion, which together serves to acquire comprehensive information and to determine the optimum operating settings.

Over the past decades, the studies on optimization of cultural conditions for threonine production were focused on E. coli and C. glutamicum. Despite optimization of glutamate [16] and GABA production [24, 25] by LAB had been conducted, there was no available report on optimization of medium formulation for threonine production by LAB. However, in our previous study, we have reported that Pediococcus pentosaceus TL-3 has the capability to produce various amino acids with exceptional ability to produce threonine and it was identified as a potential threonine producer [26]. Hence, the objectives of this study were to elucidate the effects of medium components on threonine production by $P$. pentosaceus TL-3 using PBD, followed by further optimization of the medium formulation by using CCD.

\section{Results and discussion}

\section{Plackett-Burman design}

The PBD is a useful tool for quick identification of key factors in a multivariable study [27]. In the current study, the effects of 22 medium components on threonine production by $P$. pentosaceus TL-3 were evaluated by using PBD with each medium component represented in two levels as shown in Table 1 . A dummy variable $(\mathrm{X})$ that has no chemical meaning was included in the PBD in order to determine the interactions between the variables [23]. The PBD matrix constituted of 24 experimental runs and their corresponding threonine production and cell population are presented in Table 2. The highest threonine production was detected in Run $5(56.82 \mathrm{mg} / \mathrm{L})$, followed by Run $4(42.84 \mathrm{mg} / \mathrm{L})$ and Run $13(41.26 \mathrm{mg} / \mathrm{L})$. However, the net threonine produced was achieved in the designed media and was significantly lower $(p<0.05)$ as compared to control $(63.30 \mathrm{mg} / \mathrm{L})$. This implied that further optimization was required in order to enhance the threonine production by $P$. pentosaceus TL-3.

The adequacy of the model and the significance of the medium components on threonine production by $P$. pentosaceus TL-3 were evaluated by ANOVA (Table 3). The statistical significance of the model was evaluated by Fisher's statistical test (F-test). The $p$ value of the model (0.0474) inferred that the model was significant and there was merely $4 \%$ of chance that the F-value of the model this large could occur due to noise. In addition, the coefficient of determination, $\mathrm{R}^{2}$ of the model was 0.9998 , implying that the model could explain $99 \%$ of the variation in response. Moreover, the "predicted $\mathrm{R}^{2 \text { " }}(0.9055)$ was in reasonable agreement with the "adjusted $R^{2}$ " (0.9962), where the difference was less than 0.2, indicating that the model resembles good fitness. The closer the $\mathrm{R}^{2}$ value to 1.0 , the better the correlation between the experimental and predicted values [28]. Furthermore, the adequate precision value of the present model (62.573) was greater than 4 , suggesting that the model could be used to navigate the design space. 
Table 1 Coded and real values of medium components selected in PBD

\begin{tabular}{lllll}
\hline Variables & Symbol code & Unit & \multicolumn{2}{l}{ Coded values } \\
\cline { 3 - 5 } & & & $\mathbf{- 1}$ & $\mathbf{+ 1}$ \\
\hline Glucose & $\mathrm{A}$ & $\mathrm{g} / \mathrm{L}$ & 0 & 20 \\
Sucrose & $\mathrm{B}$ & $\mathrm{g} / \mathrm{L}$ & 0 & 17.69 \\
Fructose & $\mathrm{C}$ & $\mathrm{g} / \mathrm{L}$ & 0 & 19.08 \\
Lactose & $\mathrm{D}$ & $\mathrm{g} / \mathrm{L}$ & 0 & 18.86 \\
Molasses & $\mathrm{E}$ & $\mathrm{g} / \mathrm{L}$ & 0 & 25.08 \\
Yeast extract & $\mathrm{F}$ & $\mathrm{g} / \mathrm{L}$ & 0 & 4 \\
Peptone & $\mathrm{G}$ & $\mathrm{g} / \mathrm{L}$ & 0 & 10 \\
$\mathrm{Meat} \mathrm{extract}$ & $\mathrm{H}$ & $\mathrm{g} / \mathrm{L}$ & 0 & 8 \\
$\mathrm{~K}_{2} \mathrm{HPO}_{4}$ & $\mathrm{~J}$ & $\mathrm{~g} / \mathrm{L}$ & 0 & 2 \\
$\mathrm{KH}_{2} \mathrm{PO}_{4}$ & $\mathrm{~K}$ & $\mathrm{~g} / \mathrm{L}$ & 0 & 2 \\
$\mathrm{Urea}$ & $\mathrm{L}$ & $\mathrm{g} / \mathrm{L}$ & 0 & 3 \\
$\mathrm{NH}_{4} \mathrm{NO}_{3}$ & $\mathrm{M}$ & $\mathrm{g} / \mathrm{L}$ & 0 & 5 \\
$\left(\mathrm{NH}_{4}\right)_{2} \mathrm{SO}_{4}$ & $\mathrm{~N}$ & $\mathrm{~g} / \mathrm{L}$ & 0 & 5 \\
$\left(\mathrm{NH}_{4}\right)_{2} \mathrm{HC}_{6} \mathrm{H}_{5} \mathrm{O}_{7}$ & $\mathrm{O}$ & $\mathrm{g} / \mathrm{L}$ & 0 & 2 \\
$\mathrm{NaOAC}$ & $\mathrm{P}$ & $\mathrm{g} / \mathrm{L}$ & 0 & 5 \\
$\mathrm{MgSO}_{4}$ & $\mathrm{Q}$ & $\mathrm{g} / \mathrm{L}$ & 0 & 0.2 \\
$\mathrm{MnSO}_{4}$ & $\mathrm{R}$ & $\mathrm{g} / \mathrm{L}$ & 0 & 0.04 \\
$\mathrm{Tween}_{80}$ & $\mathrm{~S}$ & $\mathrm{~mL} / \mathrm{L}$ & 0 & 1 \\
$\mathrm{FeSO}_{4}$ & $\mathrm{~T}$ & $\mathrm{~g} / \mathrm{L}$ & 0 & 0.01 \\
$\mathrm{ZnSO}_{4}$ & $\mathrm{U}$ & $\mathrm{g} / \mathrm{L}$ & 0 & 0.01 \\
$\mathrm{CuSO}_{4}$ & $\mathrm{~V}$ & $\mathrm{~g} / \mathrm{L}$ & 0 & 0.01 \\
$\mathrm{Biotin}$ & $\mathrm{g} / \mathrm{L}$ & 0 & 0.06 \\
\hline
\end{tabular}

Based on the ANOVA of threonine production (Table 3), 8 of the medium components including lactose $(\mathrm{D})$, yeast extract $(\mathrm{F})$, peptone $(\mathrm{G})$, meat extract $(\mathrm{H})$, urea (L), $\left(\mathrm{NH}_{4}\right)_{2} \mathrm{SO}_{4}(\mathrm{~N}), \mathrm{MnSO}_{4}(\mathrm{R})$, and $\mathrm{ZnSO}_{4}(\mathrm{U})$ were affected significantly $(\mathrm{p}<0.05)$ the production of threonine by $P$. pentosaceus TL-3, whereas the other medium components did not contribute significantly $(\mathrm{p}>0.05)$ to threonine production. Furthermore, the insignificance of dummy variable $(\mathrm{p}>0.05)$ suggested the possible absence of significant interactions between the variables [23]. Equation 1 expresses the production of threonine (Y) by P. pentosaceus TL-3 in terms of medium components, where the coded symbols $(\mathrm{A}-\mathrm{X})$ are as described in Table 1.

$$
\begin{aligned}
\mathrm{Y}= & 19.06-1.00 \mathrm{~A}-0.38 \mathrm{~B}-4.03 \mathrm{D}+0.88 \mathrm{E}+3.88 \mathrm{~F} \\
& +7.91 \mathrm{G}+8.21 \mathrm{H}+2.25 \mathrm{~J}-0.57 \mathrm{~K}-3.80 \mathrm{~L} \\
& -0.30 \mathrm{M}+2.76 \mathrm{~N}+0.22 \mathrm{O}-1.53 \mathrm{P} \\
& -1.22 \mathrm{Q}+5.58 \mathrm{R}-1.71 \mathrm{~S}+1.57 \mathrm{~T} \\
& -2.62 \mathrm{U}+0.80 \mathrm{~V}+0.95 \mathrm{~W}+1.44 \mathrm{X}
\end{aligned}
$$

Meanwhile, Fig. 1 depicts the effects of medium components on the production of threonine by $P$. pentosaceus TL-3. Out of the 22 studied medium components, half of the medium components including meat extract, peptone, $\mathrm{MnSO}_{4}$, yeast extract, $\left(\mathrm{NH}_{4}\right)_{2} \mathrm{SO}_{4}, \mathrm{~K}_{2} \mathrm{HPO}_{4}, \mathrm{FeSO}_{4}$, biotin, molasses, $\mathrm{CuSO}_{4}$, and $\left(\mathrm{NH}_{4}\right)_{2} \mathrm{HC}_{6} \mathrm{H}_{5} \mathrm{O}_{7}$ demonstrated positive effect on threonine production, while the other half medium components exerted negative effect on threonine production. A positive effect indicates that increased level of the medium component promotes the threonine production and vice versa [29]. Among the 11 medium components that demonstrated positive effect on threonine production, 5 of them including yeast extract, peptone, meat extract, $\left(\mathrm{NH}_{4}\right)_{2} \mathrm{SO}_{4}$, and $\mathrm{MnSO}_{4}$ were significant at p-value less than 0.05 (Table 3). In contrast, out of the 11 medium components with negative effect, 3 of them including lactose, urea, and $\mathrm{ZnSO}_{4}$ were significant at $\mathrm{p}$-value less than 0.05 .

Among the tested carbon sources (glucose, sucrose, fructose, lactose and molasses), only molasses exerted a positive effect on threonine production despite the effect was not significant $(p>0.05)$, whereas the other tested carbon sources demonstrated a negative effect on threonine production with lactose showing the highest inhibitory effect. Molasses had been widely utilized as an alternative carbon source for fermentative production of various amino acids [30] and its stimulatory effect was well reported. Moreover, Hagino and Nakayama [31] reported that molasses was the best carbon source for tryptophan production by Corynebacterium. Apart from acting as a carbon source, molasses contains abundant amount of vitamin such as niacin (vitamin $B_{3}$ ) [32], which is the precursor of nicotinamide adenine dinucleotide phosphate $\left(\mathrm{NADP}^{+}\right)$[33] that acts as coenzyme for numerous enzymes involved in the biosynthesis of threonine. For instances, the enzymes $\beta$-aspartate semialdehyde dehydrogenase and homoserine dehydrogenase require $\mathrm{NADP}^{+}$as a coenzyme for the conversion of aspartyl- $\beta$-phosphate into $\beta$-aspartate-semialdehyde [34] and the synthesis of homoserine from $\beta$-aspartatesemialdehyde $[35,36]$ respectively. Additionally, molasses also contains ample amount of pyridoxal phosphate (vita$\left.\min B_{6}\right)[37,38]$, which acts as a coenzyme for threonine synthase involving in the synthesis of threonine from phosphohomoserine [39].

Meanwhile, all the studied organic nitrogen sources (yeast extract, peptone, meat extract) exerted a positive effect on threonine production with meat extract exhibiting the most prominent effect, followed by peptone and yeast extract. Production of various amino acids by $\mathrm{LAB}$ using media containing organic nitrogen sources such as yeast extract, peptone or meat extract was well documented $[15,24,40]$. In addition, yeast extract was also employed for amino acid production by E. coli [41, 42]. The significant effect of organic nitrogen sources, particularly meat extract on threonine production by $P$. 


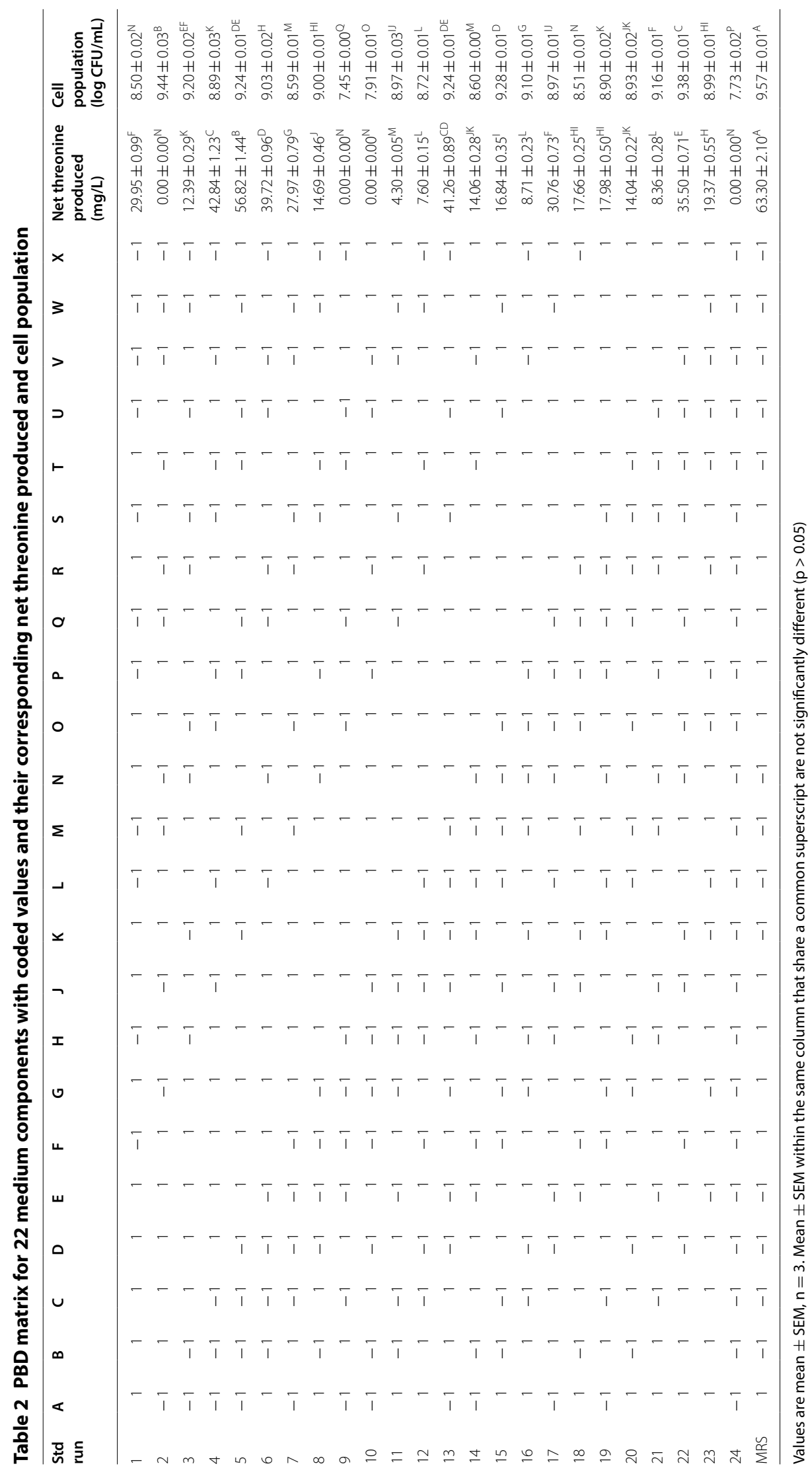


Table 3 ANOVA of PBD for the effects of medium components on threonine production by P. pentosaceus TL-3

\begin{tabular}{|c|c|c|c|c|c|c|}
\hline Source & Sum of squares & df & Mean square & F value & $\begin{array}{l}\text { p-value } \\
\text { Prob }>F\end{array}$ & \\
\hline Model & 5798.03 & 22 & 263.55 & 277.11 & 0.05 & Significant \\
\hline A-Glucose & 24.01 & 1 & 24.01 & 25.25 & 0.13 & \\
\hline B-Sucrose & 3.52 & 1 & 3.52 & 3.71 & 0.30 & \\
\hline D-Lactose & 389.05 & 1 & 389.05 & 409.07 & 0.03 & Significant \\
\hline E-Molasses & 18.70 & 1 & 18.70 & 19.66 & 0.14 & \\
\hline $\mathrm{F}$-Yeast extract & 360.50 & 1 & 360.50 & 379.06 & 0.03 & Significant \\
\hline G-Peptone & 1500.00 & 1 & 1500.00 & 1577.21 & 0.02 & Significant \\
\hline $\mathrm{H}-$ Meat extract & 1619.60 & 1 & 1619.60 & 1702.97 & 0.02 & Significant \\
\hline $\mathrm{J}-\mathrm{K}_{2} \mathrm{HPO}_{4}$ & 121.08 & 1 & 121.08 & 127.31 & 0.06 & \\
\hline $\mathrm{K}-\mathrm{KH}_{2} \mathrm{PO}_{4}$ & 7.93 & 1 & 7.93 & 8.34 & 0.21 & \\
\hline L-Urea & 347.43 & 1 & 347.43 & 365.31 & 0.03 & Significant \\
\hline $\mathrm{M}-\mathrm{NH}_{4} \mathrm{NO}_{3}$ & 2.17 & 1 & 2.17 & 2.28 & 0.37 & \\
\hline $\mathrm{N}-\left(\mathrm{NH}_{4}\right)_{2} \mathrm{SO}_{4}$ & 182.20 & 1 & 182.20 & 191.58 & 0.05 & Significant \\
\hline $\mathrm{O}-\left(\mathrm{NH}_{4}\right)_{2} \mathrm{HC}_{6} \mathrm{H}_{5} \mathrm{O}_{7}$ & 1.20 & 1 & 1.20 & 1.26 & 0.46 & \\
\hline $\mathrm{P}-\mathrm{NaOAC}$ & 56.44 & 1 & 56.44 & 59.34 & 0.08 & \\
\hline $\mathrm{Q}-\mathrm{MgSO}_{4}$ & 35.85 & 1 & 35.85 & 37.70 & 0.10 & \\
\hline $\mathrm{R}-\mathrm{MnSO}_{4}$ & 747.64 & 1 & 747.64 & 786.12 & 0.02 & Significant \\
\hline S-Tween 80 & 70.28 & 1 & 70.28 & 73.90 & 0.07 & \\
\hline $\mathrm{T}-\mathrm{FeSO}_{4}$ & 58.87 & 1 & 58.87 & 61.90 & 0.08 & \\
\hline $\mathrm{U}-\mathrm{ZnSO}_{4}$ & 164.91 & 1 & 164.91 & 173.40 & 0.05 & Significant \\
\hline $\mathrm{V}-\mathrm{CuSO}_{4}$ & 15.50 & 1 & 15.50 & 16.30 & 0.15 & \\
\hline W-Biotin & 21.58 & 1 & 21.58 & 22.69 & 0.13 & \\
\hline X-dummy & 49.58 & 1 & 49.58 & 52.14 & 0.09 & \\
\hline Residual & 0.95 & 1 & 0.95 & & & \\
\hline Cor total & 5798.98 & 23 & & & & \\
\hline
\end{tabular}

$R^{2}: 0.9998 ;$ Adj $R^{2}$ : 0.9962; Pred R²: 0.9055; Adeq precision: 62.573

pentosaceus TL-3 may due to the presence of abundant coenzymes in meat extract that are essential for enzymes involved in biosynthesis of threonine. Meat extract is rich in vitamin $B_{3}$ and vitamin $B_{6}$, which are essential for NADPH and pyridoxal phosphate biosynthesis that act as a coenzyme for $\beta$-aspartate semialdehyde dehydrogenase, homoserine dehydrogenase and threonine synthase enzymes respectively. Moreover, the organic nitrogen sources could be a source of aspartate, which is the precursor for threonine synthesis [43].

Amongst the 4 studied inorganic nitrogen sources, urea and $\left(\mathrm{NH}_{4}\right)_{2} \mathrm{SO}_{4}$ affected threonine production significantly $(\mathrm{p}<0.05)$, whereby urea exerted a negative effect and $\left(\mathrm{NH}_{4}\right)_{2} \mathrm{SO}_{4}$ demonstrated a positive effect. Davati et al. [44] has reported the use of urea for glutamate production by Corynebacterium, whereas $\left(\mathrm{NH}_{4}\right)_{2} \mathrm{SO}_{4}$ has been used for threonine production by Serratia marcescens [45] and E. coli [42, 46-48]. Furthermore, Miyajima and Shiio [49] reported that inorganic nitrogen source could affect the activity of homoserine kinase enzyme, which is responsible for the conversion of homoserine into phosphohomoserine. The homoserine kinase activity was increased by 2 -folds when $\left(\mathrm{NH}_{4}\right)_{2} \mathrm{SO}_{4}$ was added in the growth medium.

In comparison, 2 out of the 8 tested mineral sources demonstrated a significant effect $(\mathrm{p}<0.05)$ on threonine production by $P$. pentosaceus $\mathrm{TL}-3$, whereby $\mathrm{MnSO}_{4}$ displayed a significant positive effect $(\mathrm{p}<0.05)$ and $\mathrm{ZnSO}_{4}$ exhibited a significant negative effect $(\mathrm{p}<0.05)$. However, the other metal ions $\left(\mathrm{K}^{+}, \mathrm{Na}^{+}, \mathrm{Mg}^{2+}, \mathrm{Fe}^{2+}, \mathrm{Cu}^{2+}\right)$ did not contribute significantly $(\mathrm{p}>0.05)$ to threonine production. Metal ions may affect the bacterial metabolic activity due to specific ionic and water binding capacity [50]. The pronounced effect of $\mathrm{Mn}^{2+}$ on the production of LAB metabolites was well documented [51, 52]. Furthermore, the use of medium containing $\mathrm{Mn}^{2+}$ for gamma-aminobutyric acid (GABA) production by LAB [24] and threonine production by $E$. coli [42] were also reported. The significant effect of $\mathrm{Mn}^{2+}$ on threonine production might be due to its role as a cofactor for the enzymes involved in the biosynthesis of threonine. For instances, divalent cation such as $\mathrm{Mg}^{2+}, \mathrm{Mn}^{2+}$ or $\mathrm{Co}^{2+}$ 


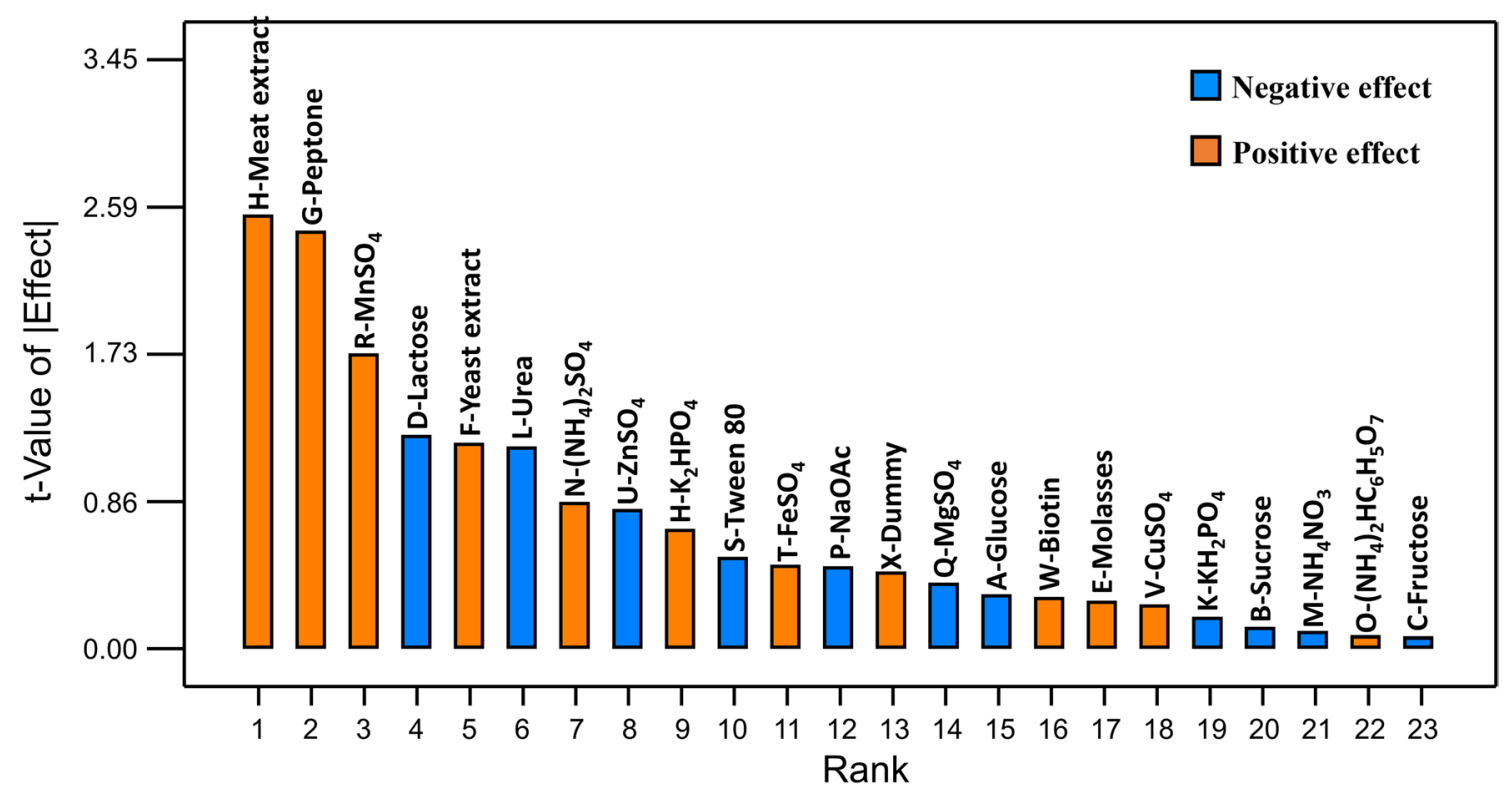

Fig. 1 Pareto chart of the effects of medium components on threonine production by P. pentosaceus TL-3

act as the physiological activator of the first enzyme involves in biosynthesis of threonine, aspartokinase, which is responsible for the phosphorylation of aspartate into aspartyl- $\beta$-phosphate [53]. Moreover, the role of divalent cations as a cofactor for the enzyme homoserine kinase was also well documented. Miyajima and Shiio [49] reported that $\mathrm{Mg}^{2+}$ was essential for the enzyme homoserine kinase, whereby the enzymatic activity was not detected when $\mathrm{Mg}^{2+}$ was absent. In addition, they also discovered that $\mathrm{Mn}^{2+}$ could potentially replace $\mathrm{Mg}^{2+}$ as a cofactor for homoserine kinase, whereby similar level of enzyme activity was detected in the presence of either $\mathrm{Mg}^{2+}$ or $\mathrm{Mn}^{2+}$ ions. The stimulatory effect of divalent cations on the enzymatic activity of homoserine kinase was also well documented by other researchers $[54,55]$.

Contradictory findings were obtained for both vitamin (biotin) and non-ionic surfactant (Tween 80) in current study, whereby both elements did not exert significant effect $(\mathrm{p}>0.05)$ on the production of threonine by P. pentosaceus TL-3. Other researchers reported that biotin was often crucial for amino acid production by $E$. coli [47] and C. glutamicum [56]. In the present study, biotin did not contribute significantly $(\mathrm{p}>0.05)$ to the production of threonine by $P$. pentosaceus TL-3, which was probably due to the use of different producer strains as compared to other studies. Another possible explanation might be the requirement of these coenzymes are often in traces amount. Hence, the use of molasses that contains ample amount of biotin [57] would be sufficient to stimulate the production of threonine by $P$. pentosaceus TL-3.
On the other hand, previous studies revealed that Tween 80 was one of the key factors affecting the production of LAB metabolites. Inclusion of Tween 80 in the growth medium enhanced the bacteriocin production by more than $50 \%$ [58], whereby Tween 80 that acted as non-ionic surfactant has facilitated the secretion of metabolites by altering the membrane fluidity of bacteria cells [59]. Despite numerous reports suggested the important role of Tween 80 on the production of LAB metabolites, yet there was limited documentation regarding the role of Tween 80 on amino acid production. However, Tween 80 has been identified as one of the key factors affecting GABA production by Lactobacillus brevis NCL912 [24] and glutamate production by Brevibacterium sp. [60].

The effects of medium components on the growth of P. pentosaceus TL-3 were also analyzed in the 24 experimental runs of PBD. The design matrix of the PBD and their respective cell population are presented in Table 2. Results obtained in the current study showed that $P$. pentosaceus TL-3 was able to grow well in most of the designed media, whereby the cell population was exceeding $8.5 \log \mathrm{CFU} / \mathrm{mL}$ in most of the experimental runs, except for run 9, 10 and 24; which exhibited a decreased cell population. One of the similarities among run 9,10 and 24 was the absence of organic nitrogen sources (peptone, meat extract, yeast extract), implying that organic nitrogen is crucial for the survival of LAB. This is in line with the findings reported by Saeed and Salam [61], where LAB is a fastidious microorganism and unable to grow on simple mineral media supplemented 
with carbon source solely. They require organic nitrogen sources in order to grow well. The highest cell population was recorded in run 2 which constituted of sucrose, fructose, lactose, molasses, yeast extract, meat extract, $\mathrm{KH}_{2} \mathrm{PO}_{4}$, urea, $\left(\mathrm{NH}_{4}\right)_{2} \mathrm{HC}_{8} \mathrm{H}_{6} \mathrm{O}_{7}, \mathrm{NaOAc}$, Tween 80 and $\mathrm{ZnSO}_{4}$ with $9.44 \log \mathrm{CFU} / \mathrm{mL}$, followed by run 22 with $9.38 \log \mathrm{CFU} / \mathrm{mL}$. Yet the cell population detected in run 2 was still significantly lower $(\mathrm{p}<0.05)$ as compared to the control that recorded $9.57 \log \mathrm{CFU} / \mathrm{mL}$ of cell population.

The adequacy of the model and significance of the medium components on the growth of $P$. pentosaceus TL-3 were evaluated by ANOVA (Table 4). The statistical significance of the model was evaluated by F-test. The $\mathrm{p}$-value of the model (0.01) inferred that the model was significant, and the occurrence of the F-value attributed to the noise was as low as $1 \%$. In addition, the $\mathrm{R}^{2}$ value of the model was highly close to 1 , indicating the strong predictive strength of the model. Furthermore, the "adjusted

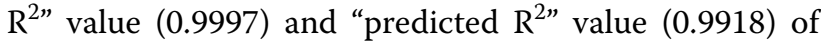
the model were in reasonable agreement, whereby the difference is less than 0.2 , indicating that the model displayed good fitness. Moreover, the adequate precision value of the model was 221.14 , suggesting a strong signal compared to noise ratio and the model could be used to navigate the design space.

Based on the ANOVA table (Table 4), 20 out of the 22 studied medium components affected the growth of the isolate significantly $(\mathrm{p}<0.05)$ and 5 of them (glucose, molasses, yeast extract, meat extract and $\left(\mathrm{NH}_{4}\right)_{2} \mathrm{SO}_{4}$ were highly significant $(\mathrm{p}<0.01)$. In contrast, urea and lactose did not contribute significantly to the growth of $P$. pentosaceus TL-3 ( $\mathrm{p}>0.05)$. Moreover, $\mathrm{p}$-value of the dummy variable $(0.01)$ implied that the interaction possibilities between the medium components, which warrant further investigation in subsequent experiment by using a higher resolution design [62]. The growth of $P$. pentosaceus TL-3 (Z) can be expressed by Eq. (2) and the coded symbols $(\mathrm{A}-\mathrm{X})$ are described in Table 1.

$$
\begin{aligned}
\mathrm{Z}= & 8.82+0.14 \mathrm{~A}+0.05 \mathrm{~B}+0.07 \mathrm{C}+0.14 \mathrm{E} \\
& +0.27 \mathrm{~F}+0.08 \mathrm{G}+0.22 \mathrm{H}-0.03 \mathrm{~J}-0.06 \mathrm{~K} \\
& +0.01 \mathrm{~L}-0.04 \mathrm{M}-0.16 \mathrm{~N}+0.07 \mathrm{O} \\
& +0.08 \mathrm{P}+0.07 \mathrm{Q}+0.06 \mathrm{R}-0.05 \mathrm{~S} \\
& +0.03 \mathrm{~T}+0.06 \mathrm{U}+0.06 \mathrm{~V}-0.06 \mathrm{~W}+0.09 \mathrm{X}
\end{aligned}
$$

Figure 2 depicts the effects of medium components on the growth of $P$. pentosaceus TL-3, whereby majority of the studied medium components exerted a positive effect on the growth, except for $\left(\mathrm{NH}_{4}\right)_{2} \mathrm{SO}_{4}$, biotin, $\mathrm{KH}_{2} \mathrm{PO}_{4}$, Tween 80, $\mathrm{NH}_{4} \mathrm{NO}_{3}$ and $\mathrm{K}_{2} \mathrm{HPO}_{4}$, which demonstrated a significant inhibitory effect $(\mathrm{p}<0.05)$. Amongst the 16 medium components with positive effect, most of them were significant at p-value less than 0.05 (Table 4), except urea and lactose $(\mathrm{p}>0.05)$. Furthermore, the tested carbon sources (glucose, sucrose, fructose, lactose and molasses) exerted a significant positive effect $(\mathrm{p}<0.05)$ on the cell growth, except lactose, suggesting that the isolate could utilize a wide variety of carbon sources for its growth. This is in line with the findings reported previously, whereby LAB could utilize various carbon sources for their growth, including simple sugars such as glucose, sucrose, mannose and etcetera [63], as well as complex carbohydrates such as agricultural wastes [64] and their hydrolysate [65].

Similar trend was observed in the organic nitrogen sources, whereby the studied organic nitrogen sources (yeast extract, peptone, meat extract) exerted a significant positive effect $(\mathrm{p}<0.05)$ on the growth of $P$. pentosaceus TL-3. The important role of organic nitrogen source on the growth of LAB has been well documented. LAB are nutritionally fastidious microorganisms and they often require exogenous supply of peptides or amino acid for growth and survival [66]. Rodrigues et al. [67] also reported that organic nitrogen sources were important elements for the growth of a probiotic bacterium, Lactococcus lactis 53. However, the organic nitrogen sources did not contribute significantly to the growth of Streptococcus thermophilus A [67], suggesting that the requirement of organic nitrogen sources for cell growth was species dependent, whereby different species of LAB has different preference on organic nitrogen source. Amongst the 3 organic nitrogen sources used in current study, yeast extract exerted the highest stimulatory effect on the growth of $P$. pentosaceus TL-3. The crucial role of yeast extract on the bacterial growth could be attributed to its rich vitamin $B$ content, which is a vital element for the growth of LAB as reported by Kadam et al. [68].

In comparison, among the inorganic nitrogen sources tested in the current study, $\left(\mathrm{NH}_{4}\right)_{2} \mathrm{SO}_{4}$ and $\mathrm{NH}_{4} \mathrm{NO}_{3}$ demonstrated a negative effect on the growth of $P$. pentosaceus TL-3, with $\left(\mathrm{NH}_{4}\right)_{2} \mathrm{SO}_{4}$ being highly significant $(\mathrm{p}<0.01)$, while $\mathrm{NH}_{4} \mathrm{NO}_{3}$ was significant at $\mathrm{p}$-value less than 0.05 . The negative effect of inorganic nitrogen revealed the inability of $\mathrm{LAB}$ to assimilate inorganic nitrogen [69]. In contrast, ammonium citrate $\left[\left(\mathrm{NH}_{4}\right)_{2} \mathrm{HC}_{6} \mathrm{H}_{5} \mathrm{O}_{7}\right]$ displayed a significant positive effect $(\mathrm{p}<0.05)$ on the growth of $P$. pentosaceus TL-3. Contradictory results were reported by Rodrigues et al. [67], whereby $\left(\mathrm{NH}_{4}\right)_{2} \mathrm{HC}_{6} \mathrm{H}_{5} \mathrm{O}_{7}$ did not influence the cell growth significantly, despite it contributed significantly on lactic acid production by Lactobacillus amylophilus GV6 [70]. In addition, urea also did not contribute significantly $(\mathrm{p}>0.05)$ to the biomass formation of $P$. pentosaceus TL-3. This agrees with the findings reported by 
Table 4 ANOVA of PBD for the effects of medium components on the growth of $P$. pentosaceus TL-3

\begin{tabular}{|c|c|c|c|c|c|c|}
\hline Source & Sum of squares & df & Mean square & F value & $\begin{array}{l}\text { p-value } \\
\text { Prob }>F\end{array}$ & \\
\hline Model & 5.99 & 22 & 0.27 & 3197.50 & 0.01 & Significant \\
\hline A-Glucose & 0.48 & 1 & 0.48 & 5684.23 & $<0.01$ & Significant \\
\hline B-Sucrose & 0.05 & 1 & 0.05 & 637.72 & 0.03 & Significant \\
\hline C-Fructose & 0.11 & 1 & 0.11 & 1314.61 & 0.02 & Significant \\
\hline E-Molasses & 0.44 & 1 & 0.44 & 5176.97 & $<0.01$ & Significant \\
\hline $\mathrm{F}$-Yeast extract & 1.81 & 1 & 1.81 & 21277.84 & $<0.01$ & Significant \\
\hline G-Peptone & 0.14 & 1 & 0.14 & 1670.85 & 0.02 & Significant \\
\hline $\mathrm{H}-$ Meat extract & 1.15 & 1 & 1.15 & 13517.33 & $<0.01$ & Significant \\
\hline $\mathrm{J}-\mathrm{K}_{2} \mathrm{HPO}_{4}$ & 0.02 & 1 & 0.02 & 215.44 & 0.04 & Significant \\
\hline $\mathrm{K}-\mathrm{KH}_{2} \mathrm{PO}_{4}$ & 0.09 & 1 & 0.09 & 1018.95 & 0.02 & Significant \\
\hline L-Urea & $<0.01$ & 1 & $<0.01$ & 13.56 & 0.17 & \\
\hline $\mathrm{M}-\mathrm{NH}_{4} \mathrm{NO}_{3}$ & 0.04 & 1 & 0.04 & 419.49 & 0.03 & Significant \\
\hline $\mathrm{N}-\left(\mathrm{NH}_{4}\right)_{2} \mathrm{SO}_{4}$ & 0.62 & 1 & 0.62 & 7297.38 & $<0.01$ & Significant \\
\hline $\mathrm{O}-\left(\mathrm{NH}_{4}\right)_{2} \mathrm{HC}_{6} \mathrm{H}_{5} \mathrm{O}_{7}$ & 0.12 & 1 & 0.12 & 1400.94 & 0.02 & Significant \\
\hline $\mathrm{P}-\mathrm{NaOAC}$ & 0.16 & 1 & 0.16 & 1822.65 & 0.01 & Significant \\
\hline $\mathrm{Q}-\mathrm{MgSO}_{4}$ & 0.11 & 1 & 0.11 & 1284.49 & 0.02 & Significant \\
\hline $\mathrm{R}-\mathrm{MnSO}_{4}$ & 0.09 & 1 & 0.09 & 1093.48 & 0.02 & Significant \\
\hline S-Tween 80 & 0.06 & 1 & 0.06 & 750.79 & 0.02 & Significant \\
\hline $\mathrm{T}-\mathrm{FeSO}_{4}$ & 0.02 & 1 & 0.02 & 198.42 & 0.05 & Significant \\
\hline $\mathrm{U}-\mathrm{ZnSO}_{4}$ & 0.10 & 1 & 0.10 & 1144.21 & 0.02 & Significant \\
\hline $\mathrm{V}-\mathrm{CuSO}_{4}$ & 0.09 & 1 & 0.09 & 1080.65 & 0.02 & Significant \\
\hline W-Biotin & 0.10 & 1 & 0.10 & 1158.44 & 0.02 & Significant \\
\hline X-dummy & 0.18 & 1 & 0.18 & 2166.55 & 0.01 & Significant \\
\hline Residual & $<0.01$ & 1 & $<0.01$ & & & \\
\hline Cor Total & 5.99 & 23 & & & & \\
\hline
\end{tabular}

$R^{2}$ : 1.0000; Adj R²: 0.9997; Pred R²: 0.9918; Adeq precision: 221.140

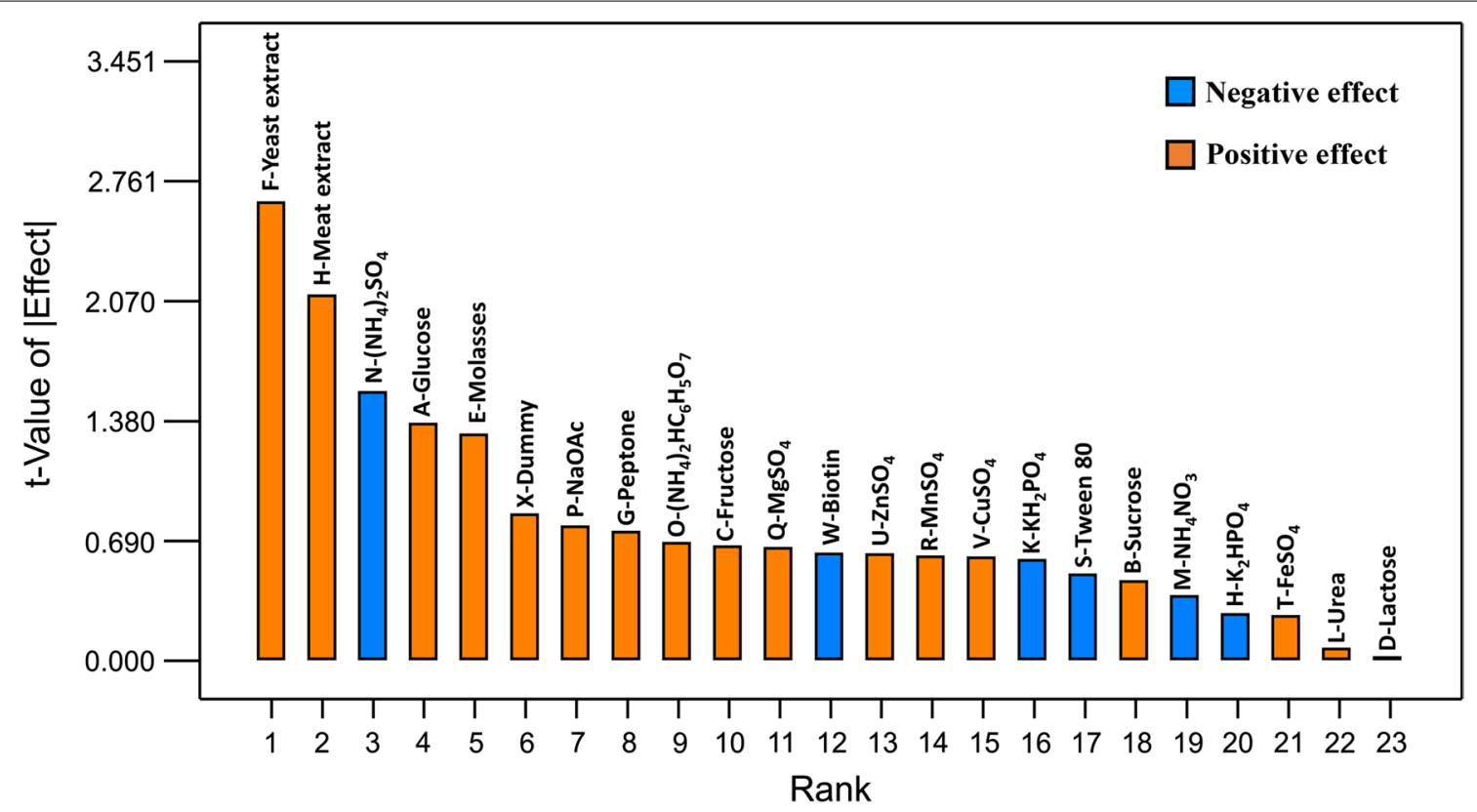

Fig. 2 Pareto chart of the effect of variables on growth of P. pentosaceus TL-3 
de Carvalho et al. [71], whereby addition of urea did not promote the growth of LAB.

Table 4 clearly shows that all the studied minerals including $\mathrm{K}_{2} \mathrm{HPO}_{4}, \mathrm{KH}_{2} \mathrm{PO}_{4}, \mathrm{NaOAc}, \mathrm{MgSO}_{4}, \mathrm{MnSO}_{4}$, $\mathrm{FeSO}_{4}, \mathrm{ZnSO}_{4}$ and $\mathrm{CuSO}_{4}$ contributed significantly $(\mathrm{p}<0.05)$ to the cell growth of $P$. pentosaceus TL-3. Majority of the studied mineral sources exhibited a stimulatory effect on the growth of the studied strain, except for $\mathrm{K}_{2} \mathrm{HPO}_{4}$ and $\mathrm{KH}_{2} \mathrm{PO}_{4}$, which affected the cell growth in a negative manner. The negative effect of $\mathrm{K}_{2} \mathrm{HPO}_{4}$ and $\mathrm{KH}_{2} \mathrm{PO}_{4}$ might be attributed to phosphate ions, which elevated the $\mathrm{pH}$ of the medium [72] and consequently retarded the growth of the acidophilic $P$. pentosaceus TL-3 that preferred acidic growing environment $[73,74]$. In contrast, the positive effects of $\mathrm{NaOAc}$ might be due to the buffering capacity of acetate ions, which maintained the $\mathrm{pH}$ of the medium in slight acidic condition, thereby enhancing the growth of the acidophilic LAB [75]. In addition, Shi et al. [25] reported that the highest production of GABA by Lactobacillus brevis TCCC 13007 was noted under acidic condition $(\mathrm{pH} 4.5)$. Meanwhile, the stimulatory effect of other mineral ions $\mathrm{Mn}^{2+}, \mathrm{Mg}^{2+}$, $\left.\mathrm{Fe}^{2+}, \mathrm{Cu}^{2+}\right)$ on $\mathrm{LAB}$ growth were well documented. The supplementation of mineral ions such as $\mathrm{Mn}^{2+}, \mathrm{Mg}^{2+}$, $\mathrm{Ca}^{2+} \mathrm{Fe}^{2+}, \mathrm{Co}^{2+}$ and $\mathrm{Cu}^{2+}$ in the growth medium of $\mathrm{LAB}$ resulted in at least 2-fold increment of growth of all the tested LAB. However, addition of $\mathrm{Zn}^{2+}$ showed stimulatory effect on the growth of some of the studied LAB strains [76]. Additionally, stimulatory effect of $\mathrm{Mn}^{2+}$ on the growth of Lactobacillus salivarius CRL 1328 was also reported by Tomas et al. [75]. This was in line with the findings obtained in the present study, whereby all mineral ions $\left.\mathrm{Mn}^{2+}, \mathrm{Mg}^{2+}, \mathrm{Fe}^{2+}, \mathrm{Cu}^{2+}, \mathrm{Zn}^{2+}\right)$ promoted the cell growth of P. pentosaceus TL-3 significantly $(\mathrm{p}<0.05)$.

Interestingly, results obtained in the present study showed that the non-ionic surfactant (Tween 80) exhibited a significant $(\mathrm{p}<0.05)$ inhibitory effect on the cell growth of $P$. pentosaceus TL-3. Oh et al. [77] has also discovered that Tween 80 did not contribute significantly to the growth of Lactobacillus casei YIT 9018. However, contradictory findings were reported by other researchers. The addition of Tween 80 enhanced the growth of LAB and other microorganisms [78, 79]. The stimulatory effect of Tween 80 could be due to the presence of oleic acid, which is a crucial growth factor for LAB [78]. Supplementation of Tween 80 allows the bacteria to incorporate oleic acid into the cell membrane, which is subsequently converted to cyclopropane fatty acids to increase the fluidity of $\mathrm{LAB}$ membranes, as well as to protect the $L A B$ from various environmental stresses such as deleterious effect of oxygen, extreme $\mathrm{pH}$ and temperature [61]. As for the effect of vitamin, biotin demonstrated a significantly negative effect $(\mathrm{p}<0.05)$ on the growth of $P$. pentosaceus TL-3. Contradictory finding was reported by Tripuraneni [80], who has reported that the supplementation of biotin enhanced the growth of various $L A B$ strains. One of the possible explanations was biotin is often required in trace amount and the presence of abundant biotin in molasses is sufficient to sustain the growth of the bacteria [81]. Further increasing of the biotin concentration may hence promoted an adverse effect.

Based on the results obtained from Plackett-Burman experiment, a validation test constituted of 7 formulated media (Table 5) was conducted to verify the effects of medium components on threonine production by $P$. pentosaceus TL- 3 . The growth and net threonine production of $P$. pentosaceus TL-3 in different formulated media and MRS medium are presented in Table 6. MRS medium was used as a control. Generally, the net threonine production by using the 7 formulated media was ranging between 2.33 and $48.89 \mathrm{mg} / \mathrm{L}$, which was significantly lower $(\mathrm{p}<0.05)$ than the MRS control medium $(60.10 \mathrm{mg} / \mathrm{L})$. Amongst the 7 formulated media, the highest net threonine production was detected in Medium 1 , which constituted of all the significant medium components. However, the net threonine production that achieved in Medium 1 was not significantly different $(p>0.05)$ as compared to Medium 3 and Medium 6 with approximately $47 \mathrm{mg} / \mathrm{L}$ of net threonine production. Furthermore, the highest cell growth was also detected in MRS control medium with $9.46 \log \mathrm{CFU} / \mathrm{mL}$, followed by Medium 4 with $9.33 \log$ CFU/mL. However, Medium 6 was selected for further optimization study since the net threonine production was not significantly different $(p>0.05)$ as compared to Medium 1 and Medium 3. Moreover, Medium 6 contained the least medium components and hence the cost of the medium was the lowest among the 3 formulated media (Medium 1, 3 and 6) that resulted the highest net threonine production.

\section{Steepest ascent}

Molasses, meat extract, $\left(\mathrm{NH}_{4}\right)_{2} \mathrm{SO}_{4}$ and $\mathrm{MnSO}_{4}$ were identified to be the most important medium components for threonine production by $P$. pentosaceus TL-3 and therefore they were selected for further optimization in this study. A steepest ascent experiment with 10 steps increment was used to determine the neighborhood of optimum concentration of these medium components. The high level $(+1)$ of the medium components in the PBD was used as the origin of the steepest ascent experiment and the first-order model (Eq. 1) generated by the PBD was employed to determine the direction and step length of each medium component. Since the selected medium components exhibited a positive effect on threonine production by $P$. pentosaceus TL-3, increasing the concentration would increase the net threonine 
Table 5 Media formulation for validation of the effects of significant medium components on threonine production

\begin{tabular}{|c|c|}
\hline Media formulation & $\begin{array}{l}\text { Concentration } \\
\text { (g/L) }\end{array}$ \\
\hline \multicolumn{2}{|l|}{ Medium 1} \\
\hline Meat extract & 8 \\
\hline Peptone & 10 \\
\hline $\mathrm{MnSO}_{4}$ & 0.04 \\
\hline Lactose & 18.86 \\
\hline Yeast extract & 4 \\
\hline Urea & 3 \\
\hline$\left(\mathrm{NH}_{4}\right)_{2} \mathrm{SO}_{4}$ & 5 \\
\hline $\mathrm{ZnSO}_{4}$ & 0.01 \\
\hline \multicolumn{2}{|l|}{ Medium 2} \\
\hline Meat extract & 8 \\
\hline Peptone & 10 \\
\hline $\mathrm{MnSO}_{4}$ & 0.04 \\
\hline Yeast extract & 4 \\
\hline$\left(\mathrm{NH}_{4}\right)_{2} \mathrm{SO}_{4}$ & 5 \\
\hline \multicolumn{2}{|l|}{ Medium 3} \\
\hline Meat extract & 8 \\
\hline Peptone & 10 \\
\hline $\mathrm{MnSO}_{4}$ & 0.04 \\
\hline Yeast extract & 4 \\
\hline$\left(\mathrm{NH}_{4}\right)_{2} \mathrm{SO}_{4}$ & 5 \\
\hline Molasses & 25.08 \\
\hline \multicolumn{2}{|l|}{ Medium 4} \\
\hline Meat extract & 8 \\
\hline Peptone & 10 \\
\hline $\mathrm{MnSO}_{4}$ & 0.04 \\
\hline Yeast extract & 4 \\
\hline$\left(\mathrm{NH}_{4}\right)_{2} \mathrm{SO}_{4}$ & 5 \\
\hline $\mathrm{K}_{2} \mathrm{HPO}_{4}$ & 2 \\
\hline $\mathrm{FeSO}_{4}$ & 0.01 \\
\hline Biotin & 0.06 \\
\hline Molasses & 25.08 \\
\hline $\mathrm{CuSO}_{4}$ & 0.01 \\
\hline$\left(\mathrm{NH}_{4}\right)_{2} \mathrm{HC}_{6} \mathrm{H}_{5} \mathrm{O}_{7}$ & 2 \\
\hline \multicolumn{2}{|l|}{ Medium 5} \\
\hline Molasses & 25.08 \\
\hline Peptone & 10 \\
\hline$\left(\mathrm{NH}_{4}\right)_{2} \mathrm{SO}_{4}$ & 5 \\
\hline $\mathrm{MnSO}_{4}$ & 0.04 \\
\hline \multicolumn{2}{|l|}{ Medium 6} \\
\hline Molasses & 25.08 \\
\hline Meat extract & 8 \\
\hline$\left(\mathrm{NH}_{4}\right)_{2} \mathrm{SO}_{4}$ & 5 \\
\hline $\mathrm{MnSO}_{4}$ & 0.04 \\
\hline \multicolumn{2}{|l|}{ Medium 7} \\
\hline Molasses & 25.08 \\
\hline Yeast extract & 4 \\
\hline$\left(\mathrm{NH}_{4}\right)_{2} \mathrm{SO}_{4}$ & 5 \\
\hline $\mathrm{MnSO}_{4}$ & 0.04 \\
\hline
\end{tabular}

Table 6 Growth and net threonine produced by $P$. pentosaceus TL-3 in different media

\begin{tabular}{llc}
\hline Media & $\begin{array}{l}\text { Cell population } \\
\text { (Log CFU/mL) }\end{array}$ & $\begin{array}{l}\text { Net threonine } \\
\text { produced }(\mathbf{m g} / \mathbf{L})\end{array}$ \\
\hline 1 & $8.94 \pm 0.02^{\mathrm{D}}$ & $48.89 \pm 5.57^{\mathrm{B}}$ \\
2 & $8.69 \pm 0.05^{\mathrm{F}}$ & $2.33 \pm 1.24^{\mathrm{D}}$ \\
3 & $9.15 \pm 0.01^{\mathrm{C}}$ & $47.12 \pm 3.33^{\mathrm{B}}$ \\
4 & $9.33 \pm 0.01^{\mathrm{B}}$ & $31.99 \pm 4.06^{\mathrm{C}}$ \\
5 & $8.69 \pm 0.02^{\mathrm{F}}$ & $29.36 \pm 1.97^{\mathrm{C}}$ \\
6 & $8.99 \pm 0.02^{\mathrm{D}}$ & $47.14 \pm 0.62^{\mathrm{B}}$ \\
7 & $8.83 \pm 0.05^{\mathrm{E}}$ & $29.95 \pm 0.20^{\mathrm{C}}$ \\
MRS & $9.46 \pm 0.01^{\mathrm{A}}$ & $60.10 \pm 4.04^{\mathrm{A}}$
\end{tabular}

Values are mean \pm standard error of the mean (SEM), $\mathrm{n}=3$. Mean $\pm S E M$ within the same column that share a different superscript are significantly different $(p>0.05)$

production. Hence, the concentration of medium components was moved along the path of steepest ascent. The coefficient of meat extract (the largest among the 4 medium components) was used as the standard for calculation of step length. Thus, the concentrations of molasses, $\left(\mathrm{NH}_{4}\right)_{2} \mathrm{SO}_{4}$ and $\mathrm{MnSO}_{4}$ were increased by $5.5 \%, 17 \%$ and $34 \%$ respectively when the concentration of meat extract was increased by $50 \%$ as presented in Table 7 .

Table 8 presents the cell population and net threonine production by $P$. pentosaceus TL-3 in the steepest ascent experiment. Generally, the cell population increased progressively from run $1(8.71 \log \mathrm{CFU} / \mathrm{mL})$ to run $6(9.23$ $\log \mathrm{CFU} / \mathrm{mL}$ ). However, the reduction of cell population was noted when the concentration of medium components was increased further, indicating that higher concentration exerted inhibitory effect on the cell growth. Similar trend was observed in the threonine production, whereby the net threonine production was increased steadily from run $1(45.42 \mathrm{mg} / \mathrm{L})$ to run $5(116.83 \mathrm{mg} / \mathrm{L})$. The highest net threonine production was detected in run 5 with $30.6 \mathrm{~g} / \mathrm{L}$ molasses, $24 \mathrm{~g} / \mathrm{L}$ meat extract, $8.4 \mathrm{~g} / \mathrm{L}$ $\left(\mathrm{NH}_{4}\right)_{2} \mathrm{SO}_{4}$ and $0.096 \mathrm{~g} / \mathrm{L} \mathrm{MnSO}_{4}$. After 4 steps of increment, the net threonine production was improved by approximately 3 folds as compared to the origin (run 1). Moreover, the net threonine production achieved at run 5 was significantly higher $(\mathrm{p}<0.05)$ as compared to the control (MRS medium). Inhibitory effect on threonine production by $P$. pentosaceus TL-3 was noted when the concentration of the medium components was increased further. Hence, the concentration of the medium components at run 5 was selected as the center point for further optimization in the subsequent CCD experiment.

\section{Central composite design}

Five levels of concentrations were assigned to each medium component as shown in Table 9. A 30 
Table 7 Steepest ascent for threonine production by $P$. pentosaceus TL-3

\begin{tabular}{|c|c|c|c|c|c|}
\hline \multirow[t]{2}{*}{ No. } & \multirow[t]{2}{*}{ Run } & \multicolumn{4}{|c|}{ Medium compenet level, g/L } \\
\hline & & $\begin{array}{l}\text { Molasses } \\
\text { (A) }\end{array}$ & $\begin{array}{l}\text { Meat } \\
\text { extract } \\
\text { (B) }\end{array}$ & $\left(\mathrm{NH}_{4}\right)_{2} \mathrm{SO}_{4}(\mathrm{C})$ & $\begin{array}{l}\mathrm{MnSO}_{4} \\
\text { (D) }\end{array}$ \\
\hline & $\Delta$ & 1.38 & 4 & 0.85 & 0.014 \\
\hline 1 & Origin & 25.08 & 8 & 5.00 & 0.040 \\
\hline 2 & Origin $+\Delta$ & 26.46 & 12 & 5.85 & 0.054 \\
\hline 3 & Origin $+2 \Delta$ & 27.84 & 16 & 6.70 & 0.068 \\
\hline 4 & Origin $+3 \Delta$ & 29.22 & 20 & 7.55 & 0.082 \\
\hline 5 & Origin $+4 \Delta$ & 30.60 & 24 & 8.40 & 0.096 \\
\hline 6 & Origin $+5 \Delta$ & 31.98 & 28 & 9.25 & 0.110 \\
\hline 7 & Origin $+6 \triangle$ & 33.36 & 32 & 10.10 & 0.124 \\
\hline 8 & Origin $+7 \triangle$ & 34.74 & 36 & 10.95 & 0.138 \\
\hline 9 & Origin $+8 \Delta$ & 36.12 & 40 & 11.80 & 0.152 \\
\hline 10 & Origin $+9 \Delta$ & 37.50 & 44 & 12.65 & 0.166 \\
\hline 11 & Origin $+10 \Delta$ & 38.88 & 48 & 13.50 & 0.180 \\
\hline
\end{tabular}

experimental runs CCD was suggested and their corresponding experimental and predicted net threonine production are presented in Table 10. The highest net threonine production was detected in run 25 to run 30 , which represented the center point of the CCD with approximately $120 \mathrm{mg} / \mathrm{L}$ of net threonine produced, followed by run 16 , which constituted of high level $(+1)$ of all the 4 studied medium components with up to $100 \mathrm{mg} / \mathrm{L}$ of net threonine produced. The net threonine produced detected in run 25 to run 30 was significantly higher $(\mathrm{p}<0.05)$ than the control (MRS medium), which recorded $60.47 \mathrm{mg} / \mathrm{L}$ of net threonine produced.

The ANOVA of the regression models for threonine production by $P$. pentosaceus TL-3 is shown in Table 11 . Amongst the 4 tested models, the data were significantly $(\mathrm{p}<0.05)$ best fitted to a quadratic polynomial model, whereas the linear, crossproduct and cubic models were not significant $(p>0.05)$. Moreover, high adjusted $R^{2}$ value (0.9744) and predicted $R^{2}$ value $(0.9379)$ were observed in the quadratic model with insignificant lack of fit $(p>0.05)$. This indicated that the high predictive strength and goodness of fit of the model. The high predictive strength of the model was further supported by the closeness between the experimental and predicted net threonine produced as shown in Table 10. Furthermore, the quadratic model was not aliased. Hence, the quadratic model was chosen as the best model to represent the threonine production by $P$. pentosaceus TL-3.

The effects of molasses, meat extract, $\left(\mathrm{NH}_{4}\right)_{2} \mathrm{SO}_{4}$ and $\mathrm{MnSO}_{4}$ on the net threonine production by $P$. pentosaceus TL-3 (Y) can be expressed by Eq. (3) with coded symbols (A-D) as shown in Table 9.

$$
\begin{aligned}
\mathrm{Y}= & 121.27+2.37 \mathrm{~A}+5.94 \mathrm{~B}+4.82 \mathrm{C}+1.74 \mathrm{D} \\
& +0.35 \mathrm{AB}-0.1 \mathrm{AC}-0.012 \mathrm{AD}+1.65 \mathrm{BC} \\
& +0.98 \mathrm{BD}-0.87 \mathrm{CD}-8.91 \mathrm{~A}^{2}-9.95 \mathrm{~B}^{2} \\
& -11.61 \mathrm{C}^{2}-6.19 \mathrm{D}^{2}
\end{aligned}
$$

The adequacy of quadratic model and significance of the variables on threonine production by $P$. pentosaceus TL-3 were evaluated by ANOVA (Table 12). The p-value of the model was less than 0.01 , inferring that the model was highly significant and the F-value of the model that could be due to noise was less than $1 \%$. In addition, the coefficient of determination, $\mathrm{R}^{2}$ of the model was 0.9868 , implying that the model is capable of explaining $98.7 \%$ of the variation in response. Moreover, the predicted $\mathrm{R}^{2}$ $(0.9379)$ was in reasonable agreement with the adjusted $R^{2}(0.9744)$ and both $R^{2}$ values were very close to 1 . Moreover, the p-value of lack of fit (0.33) implied that the lack of fit was not significant, reflecting the high predictive strength of the model and great correlation between the experimental and predicted values [28]. Additionally, the adequate precision value of the model (28.578) was greater than 4 , indicating an adequate signal compared to noise and the model could be used to navigate the design space. Based on Table 12, the linear coefficients (A, B, C, D) and quadratic coefficients $\left(\mathrm{A}^{2}, \mathrm{~B}^{2}, \mathrm{C}^{2}, \mathrm{D}^{2}\right)$ were highly significant $(p<0.01)$, while one of the interaction coefficient $(\mathrm{BC})$ was significant at $\mathrm{p}$-value less than 0.05 .

The three-dimensional response surface curves (Figs. 3, $4,5,6,7$ and 8 ) were subsequently plotted to illustrate the interactions between the medium components graphically. Generally, the highest net threonine produced was detected when the level of each medium component was near the center point. Figure 3 depicts the threedimensional plot of threonine production by $P$. pentosaceus TL-3 as the functions of molasses and meat extract, whereby the $\left(\mathrm{NH}_{4}\right)_{2} \mathrm{SO}_{4}$ and $\mathrm{MnSO}_{4}$ were fixed at the center point $(8.4 \mathrm{~g} / \mathrm{L}, 0.096 \mathrm{~g} / \mathrm{L})$. The maximum response was detected when the level of both molasses and meat extract was near 0 . Increasing or decreasing the concentration of any of these medium components reduced the net threonine produced. Based on the p-value of the ANOVA analysis (Table 12), it implied that there were no significant interactions $(p>0.05)$ between the 2 variables.

Figure 4 illustrates the combined effects of molasses and $\left(\mathrm{NH}_{4}\right)_{2} \mathrm{SO}_{4}$ on threonine production by P. pentosaceus TL-3, whereby the concentrations of meat extract and $\mathrm{MnSO}_{4}$ were kept at the center point $(24 \mathrm{~g} / \mathrm{L}$, $0.096 \mathrm{~g} / \mathrm{L}$ ). Based on the ANOVA result (Table 12), both molasses and $\left(\mathrm{NH}_{4}\right)_{2} \mathrm{SO}_{4}$ affected threonine production significantly $(\mathrm{p}<0.05)$. However, the interaction between the two variables did not contribute significantly to the production of threonine by $P$. pentosaceus TL-3 $(\mathrm{p}>0.05)$ 
Table 8 Cell population and net threonine produced by $P$. pentosaceus TL-3 in different media in steepest ascent experiment

\begin{tabular}{lll}
\hline Run & $\begin{array}{l}\text { Cell population } \\
(\mathbf{l o g} \text { CFU/mL) }\end{array}$ & $\begin{array}{l}\text { Net threonine produced } \\
(\mathbf{m g} / \mathbf{L})\end{array}$ \\
\hline 1 & $8.71 \pm 0.02^{\mathrm{F}}$ & $45.42 \pm 0.11^{\mathrm{H}}$ \\
2 & $8.95 \pm 0.01^{\mathrm{E}}$ & $48.62 \pm 0.10^{\mathrm{G}}$ \\
3 & $9.00 \pm 0.01^{\mathrm{D}}$ & $60.34 \pm 0.91^{\mathrm{F}}$ \\
4 & $9.01 \pm 0.02^{\mathrm{D}}$ & $88.96 \pm 0.36^{\mathrm{C}}$ \\
5 & $9.20 \pm 0.01^{\mathrm{B}}$ & $116.83 \pm 0.29^{\mathrm{A}}$ \\
6 & $9.23 \pm 0.01^{\mathrm{B}}$ & $95.37 \pm 0.14^{\mathrm{B}}$ \\
7 & $9.03 \pm 0.01^{\mathrm{D}}$ & $73.14 \pm 2.14^{\mathrm{D}}$ \\
8 & $9.15 \pm 0.01^{\mathrm{C}}$ & $57.77 \pm 0.71^{\mathrm{F}}$ \\
9 & $9.19 \pm 0.01^{\mathrm{B}}$ & $48.65 \pm 0.40^{\mathrm{G}}$ \\
10 & $9.14 \pm 0.01^{\mathrm{C}}$ & $36.99 \pm 0.84^{\mathrm{I}}$ \\
11 & $9.12 \pm 0.01^{\mathrm{C}}$ & $19.47 \pm 0.16^{\mathrm{J}}$ \\
MRS & $9.32 \pm 0.01^{\mathrm{A}}$ & $64.09 \pm 2.46^{\mathrm{E}}$ \\
\hline
\end{tabular}

Values are mean \pm standard error of the mean (SEM), $n=3$. Mean \pm SEM within the same column that share similar superscript are not significantly different $(p>0.05)$

and the highest net threonine produced was detected when the level of both variables was near the center point. Meanwhile, Fig. 5 displays the three dimensional surface plot as functions of molasses and $\mathrm{MnSO}_{4}$, whereby the concentrations of meat extract and $\left(\mathrm{NH}_{4}\right)_{2} \mathrm{SO}_{4}$ were fixed at the center point $(24 \mathrm{~g} / \mathrm{L}, 8.4 \mathrm{~g} / \mathrm{L})$. Similarly, the interaction between the 2 variables was not significant $(p>0.05)$ and the highest response was observed when both variables were in the range of -1 to +1 .

On the other hand, the interaction between meat extract and $\left(\mathrm{NH}_{4}\right)_{2} \mathrm{SO}_{4}$ is shown in Fig. 6, whereby the concentrations of molasses and $\mathrm{MnSO}_{4}$ were set at the center point $(30.60 \mathrm{~g} / \mathrm{L}, 0.096 \mathrm{~g} / \mathrm{L})$.The highest net threonine produced was detected when the level of meat extract was between 0 and +1 , while the concentration of $\left(\mathrm{NH}_{4}\right)_{2} \mathrm{SO}_{4}$ was kept near to the center point. Based on the ANOVA results (Table 12), the interaction effect between meat extract and $\left(\mathrm{NH}_{4}\right)_{2} \mathrm{SO}_{4}$ was significant at p-value less than 0.05 . Figure 7 depicts the three dimensional surface plot of net threonine produced as a function of meat extract and $\mathrm{MnSO}_{4}$, where the level of molasses and $\left(\mathrm{NH}_{4}\right)_{2} \mathrm{SO}_{4}$ were kept at the center point $(30.60 \mathrm{~g} / \mathrm{L}, 8.4 \mathrm{~g} / \mathrm{L})$. The highest net threonine produced was observed when the level of meat extract was between 0 and +1 , while the level of $\mathrm{MnSO}_{4}$ was varied between -1 and +1 . However, the ANOVA results (Table 12) demonstrated that the interaction between meat extract and $\mathrm{MnSO}_{4}$ did not contribute significantly $(\mathrm{p}>0.05)$ to the production of threonine by $P$. pentosaceus TL-3.

The combined effects of $\left(\mathrm{NH}_{4}\right)_{2} \mathrm{SO}_{4}$ and $\mathrm{MnSO}_{4}$ on threonine production by the producer strain was illustrated in Fig. 8, whereby the levels of molasses and meat extract were fixed at the center point $(30.60 \mathrm{~g} / \mathrm{L}$, $24 \mathrm{~g} / \mathrm{L}$ ). The highest threonine production was detected when the levels of $\left(\mathrm{NH}_{4}\right)_{2} \mathrm{SO}_{4}$ and $\mathrm{MnSO}_{4}$ were near the center point. Nevertheless, ANOVA analysis (Table 12) showed that the interaction effect between $\left(\mathrm{NH}_{4}\right)_{2} \mathrm{SO}_{4}$ and $\mathrm{MnSO}_{4}$ was not significant $(\mathrm{p}>0.05)$. The optimized level of each medium components was then computed by using Design Expert statistical software version 9.0.6.2 (State-Ease Inc, Minneapolis) with the setting of all medium components at the range of -1 to +1 and maximum response. By taking into consideration of these criteria, the optimum concentration of molasses, meat extract, $\left(\mathrm{NH}_{4}\right)_{2} \mathrm{SO}_{4}$ and $\mathrm{MnSO}_{4}$ were found to be $30.79 \mathrm{~g} / \mathrm{L}, 25.30 \mathrm{~g} / \mathrm{L}, 8.59 \mathrm{~g} / \mathrm{L}$, and $0.098 \mathrm{~g} / \mathrm{L}$ respectively with a predicted net threonine production of $123.07 \mathrm{mg} / \mathrm{L}$. Validation of the statistical model was performed by cultivating $P$. pentosaceus TL-3 in the suggested optimized medium and an amount of $125.98 \mathrm{mg} / \mathrm{L}$ net threonine was produced. The production of threonine by $P$. pentosaceus TL- 3 in the optimized medium was enhanced approximately by 2 folds as compared to MRS medium.

\section{Conclusions}

Molasses, meat extract, $\left(\mathrm{NH}_{4}\right)_{2} \mathrm{SO}_{4}$ and $\mathrm{MnSO}_{4}$ were identified to be the most essential medium components for threonine production by $P$. pentosaceus TL-3 via PBD and selected for further optimization. The optimum operating region of each medium component was determined by using steepest ascent method. The highest net threonine production of $116.83 \mathrm{mg} / \mathrm{L}$ was detected in run

Table 9 Coded and real values of medium compenents for CCD of threonine production by P. pentosaceus TL-3

\begin{tabular}{|c|c|c|c|c|c|c|}
\hline \multirow[t]{2}{*}{ Variables } & \multirow[t]{2}{*}{ Coded symbol } & \multicolumn{5}{|c|}{ Coded values } \\
\hline & & $-a$ & -1 & 0 & +1 & $+a$ \\
\hline Molasses & A & 27.84 & 29.22 & 30.60 & 31.98 & 33.36 \\
\hline Meat extract & B & 16 & 20 & 24 & 28 & 32 \\
\hline$\left(\mathrm{NH}_{4}\right)_{2} \mathrm{SO}_{4}$ & C & 6.7 & 7.55 & 8.4 & 9.25 & 10.10 \\
\hline $\mathrm{MnSO}_{4}$ & $\mathrm{D}$ & 0.067 & 0.082 & 0.096 & 0.110 & 0.124 \\
\hline
\end{tabular}


Table 10 CCD matrix with coded value and their corresponding experimental and predicted net threonine produced by $P$. pentosaceus TL-3

\begin{tabular}{|c|c|c|c|c|c|c|}
\hline \multirow[t]{2}{*}{ Std run } & \multirow[t]{2}{*}{ A } & \multirow[t]{2}{*}{ B } & \multirow[t]{2}{*}{ C } & \multirow[t]{2}{*}{ D } & \multicolumn{2}{|c|}{ Net threonine produced (mg/L) } \\
\hline & & & & & Experimental & Predicted $^{\mathbf{a}}$ \\
\hline 1 & -1 & -1 & -1 & -1 & $71.90 \pm 0.19^{L}$ & 71.79 \\
\hline 2 & 1 & -1 & -1 & -1 & $75.28 \pm 0.19^{K}$ & 75.95 \\
\hline 3 & -1 & 1 & -1 & -1 & $76.98 \pm 0.24^{K}$ & 77.71 \\
\hline 4 & 1 & 1 & -1 & -1 & $84.67 \pm 0.50^{\mathrm{H}}$ & 83.27 \\
\hline 5 & -1 & -1 & 1 & -1 & $79.72 \pm 0.87^{1}$ & 80.07 \\
\hline 6 & 1 & -1 & 1 & -1 & $85.62 \pm 0.20^{\mathrm{H}}$ & 83.83 \\
\hline 7 & -1 & 1 & 1 & -1 & $89.11 \pm 0.41^{G}$ & 92.59 \\
\hline 8 & 1 & 1 & 1 & -1 & $98.25 \pm 0.41^{\mathrm{D}}$ & 97.75 \\
\hline 9 & -1 & -1 & -1 & 1 & $75.87 \pm 0.30^{K}$ & 75.07 \\
\hline 10 & 1 & -1 & -1 & 1 & $81.66 \pm 0.09^{1}$ & 79.19 \\
\hline 11 & -1 & 1 & -1 & 1 & $82.09 \pm 0.06^{1}$ & 84.91 \\
\hline 12 & 1 & 1 & -1 & 1 & $92.07 \pm 0.42^{F}$ & 90.43 \\
\hline 13 & -1 & -1 & 1 & 1 & $77.48 \pm 0.11^{\mathrm{JK}}$ & 79.87 \\
\hline 14 & 1 & -1 & 1 & 1 & $85.61 \pm 0.09^{\mathrm{H}}$ & 83.59 \\
\hline 15 & -1 & 1 & 1 & 1 & $98.27 \pm 0.29^{D}$ & 96.31 \\
\hline 16 & 1 & 1 & 1 & 1 & $100.29 \pm 0.17^{D}$ & 101.43 \\
\hline 17 & -2 & 0 & 0 & 0 & $84.58 \pm 0.46^{\mathrm{H}}$ & 80.99 \\
\hline 18 & 2 & 0 & 0 & 0 & $86.42 \pm 0.26^{\mathrm{H}}$ & 90.27 \\
\hline 19 & 0 & -2 & 0 & 0 & $67.87 \pm 0.13^{\mathrm{M}}$ & 69.59 \\
\hline 20 & 0 & 2 & 0 & 0 & $94.80 \pm 0.24^{\mathrm{E}}$ & 93.35 \\
\hline 21 & 0 & 0 & -2 & 0 & $64.24 \pm 0.15^{\mathrm{N}}$ & 65.19 \\
\hline 22 & 0 & 0 & 2 & 0 & $85.14 \pm 0.16^{\mathrm{H}}$ & 84.47 \\
\hline 23 & 0 & 0 & 0 & -2 & $93.91 \pm 0.13^{\mathrm{EF}}$ & 93.03 \\
\hline 24 & 0 & 0 & 0 & 2 & $98.88 \pm 0.22^{\mathrm{D}}$ & 99.99 \\
\hline 25 & 0 & 0 & 0 & 0 & $118.84 \pm 1.58^{C}$ & 121.27 \\
\hline 26 & 0 & 0 & 0 & 0 & $118.93 \pm 0.79^{c}$ & 121.27 \\
\hline 27 & 0 & 0 & 0 & 0 & $124.95 \pm 2.26^{\mathrm{A}}$ & 121.27 \\
\hline 28 & 0 & 0 & 0 & 0 & $122.01 \pm 2.60^{\mathrm{AB}}$ & 121.27 \\
\hline 29 & 0 & 0 & 0 & 0 & $120.24 \pm 1.55^{\mathrm{BC}}$ & 121.27 \\
\hline 30 & 0 & 0 & 0 & 0 & $122.65 \pm 1.25^{\mathrm{AB}}$ & 121.27 \\
\hline MRS & - & - & - & - & $60.47 \pm 0.72^{\circ}$ & - \\
\hline
\end{tabular}

Values are mean \pm standard error of mean (SEM), $n=3$. Mean \pm SEM within the same column that share different superscript are significantly different $(p<0.05)$

a Predicted net threonine produced was calculated based on Eq. 3

Table 11 ANOVA of regression model for threonine production by P. pentosaceus TL-3

\begin{tabular}{|c|c|c|c|c|c|}
\hline Source & Sequential $p$-value & Lack of fit $p$-value & Adjusted R-squared & Predicted R-squared & \\
\hline Linear & 0.2610 & 0.0001 & 0.0530 & 0.0166 & \\
\hline Crossproduct & 0.9998 & $<0.0001$ & -0.2333 & -0.3772 & \\
\hline Quadratic & $<0.0001$ & 0.3344 & 0.9744 & 0.9379 & Suggested \\
\hline Cubic & 0.1724 & 0.6420 & 0.9839 & 0.9043 & Aliased \\
\hline
\end{tabular}

5. Further increment of the concentrations of medium components reduced the net threonine produced. Thus, the operating parameters of run 5 was selected as center point for further optimization in CCD. The optimum concentration of molasses, meat extract, $\left(\mathrm{NH}_{4}\right)_{2} \mathrm{SO}_{4}$ and $\mathrm{MnSO}_{4}$ were found to be $30.79 \mathrm{~g} / \mathrm{L}, 25.30 \mathrm{~g} / \mathrm{L}, 8.59 \mathrm{~g} / \mathrm{L}$, 
Table 12 ANOVA for quadratic model of net threonine produced by $P$. pentosaceus TL-3

\begin{tabular}{|c|c|c|c|c|c|c|}
\hline Source & Sum of squares & df & Mean square & F value & $\begin{array}{l}\text { p-value } \\
\text { Prob }>F\end{array}$ & \\
\hline Model & 8625.09 & 14 & 616.08 & 79.98 & $<0.01$ & Significant \\
\hline A & 129.29 & 1 & 129.29 & 16.79 & $<0.01$ & Significant \\
\hline B & 845.61 & 1 & 845.61 & 109.78 & $<0.01$ & Significant \\
\hline C & 557.25 & 1 & 557.25 & 72.35 & $<0.01$ & Significant \\
\hline $\mathrm{D}$ & 72.66 & 1 & 72.66 & 9.43 & $<0.01$ & Significant \\
\hline$A B$ & 1.97 & 1 & 1.97 & 0.26 & 0.62 & \\
\hline$A C$ & 0.17 & 1 & 0.17 & 0.022 & 0.88 & \\
\hline$A D$ & $2.275 E-3$ & 1 & $2.275 E-3$ & $2.953 \mathrm{E}-4$ & 0.99 & \\
\hline$B C$ & 43.61 & 1 & 43.61 & 5.66 & 0.03 & Significant \\
\hline $\mathrm{BD}$ & 15.22 & 1 & 15.22 & 1.98 & 0.18 & \\
\hline$C D$ & 12.08 & 1 & 12.08 & 1.57 & 0.23 & \\
\hline$A^{2}$ & 2176.96 & 1 & 2176.96 & 282.63 & $<0.01$ & Significant \\
\hline$B^{2}$ & 2715.77 & 1 & 2715.77 & 352.58 & $<0.01$ & Significant \\
\hline$C^{2}$ & 3698.22 & 1 & 3698.22 & 480.13 & $<0.01$ & Significant \\
\hline$D^{2}$ & 1049.34 & 1 & 1049.34 & 136.23 & $<0.01$ & Significant \\
\hline Residual & 115.54 & 15 & 7.70 & & & \\
\hline Lack of Fit & 87.06 & 10 & 8.71 & 1.53 & 0.33 & Not significant \\
\hline Pure Error & 28.48 & 5 & 5.70 & & & \\
\hline Cor Total & 8740.62 & 29 & & & & \\
\hline
\end{tabular}

$R^{2}$ : 0.9868; Adj R²: 0.9744; Pred R²: 0.9379; Adeq precision: 28.578

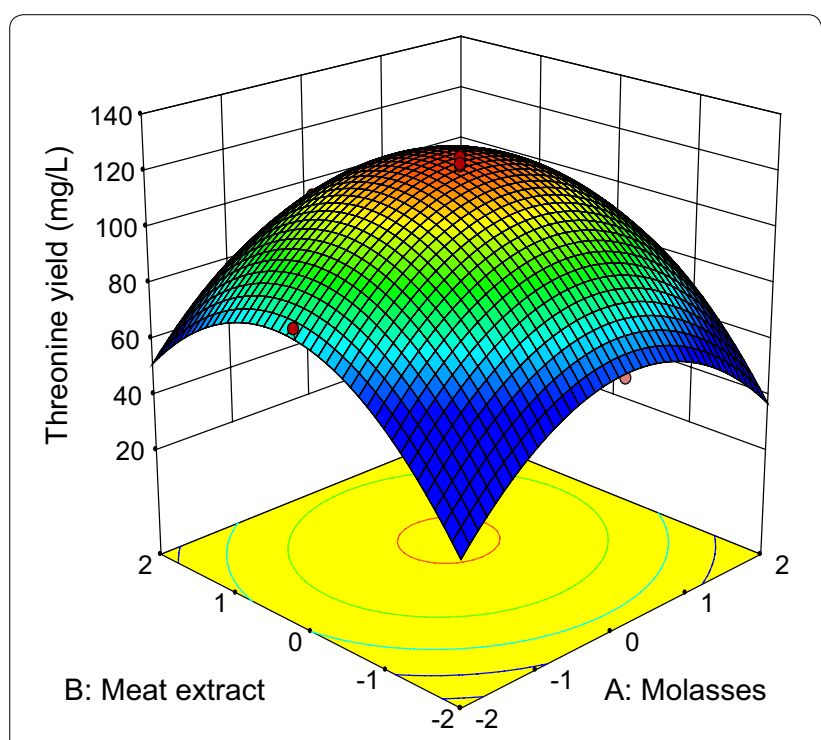

Fig. 3 Response surface of net threonine produced by P. pentosaceus TL-3 as functions of molasses and meat extract

and $0.098 \mathrm{~g} / \mathrm{L}$ respectively, based on the model obtained in $\mathrm{CCD}$ with a predicted net threonine production of $123.07 \mathrm{mg} / \mathrm{L}$. The statistical model was subsequently validated by cultivating the producer strain in the optimized medium and up to $125.98 \mathrm{mg} / \mathrm{L}$ of net threonine produced was detected, which was not significantly different $(\mathrm{p}>0.05)$ as compared to the predicted amount. The net threonine produced by $P$. pentosaceus TL-3 in the optimized medium was enhanced approximately by 2 folds in comparison to the control MRS medium through RSM optimization approach.

\section{Materials and methods}

\section{Microorganism and inoculum preparation}

The threonine producing LAB employed in current study, P. pentosaceus TL-3, was previously isolated from Malaysian fermented food, Tempeh [82]. The bacterial strain was obtained from the Laboratory of Industrial Biotechnology, Department of Bioprocess Technology, Faculty of Biotechnology and Biomolecular Sciences, Universiti Putra Malaysia. The culture was grown in de Man, Rogosa and Sharpe (MRS) medium (Merck, Germany) and preserved in MRS medium supplemented with $20 \%$ (v/v) glycerol (Merck, Germany) at $-20{ }^{\circ} \mathrm{C}$ as described by Kareem et al. [83]. The active culture was washed once with sterile $0.85 \%$ (w/v) $\mathrm{NaCl}$ (Merck, Germany) solution and adjusted to $10^{9} \mathrm{CFU} / \mathrm{mL}$ prior to use as inoculum for the experiment [84].

\section{Experimental design}

The effects of medium components on threonine production by $P$. pentosaceus TL-3 were first evaluated by using 


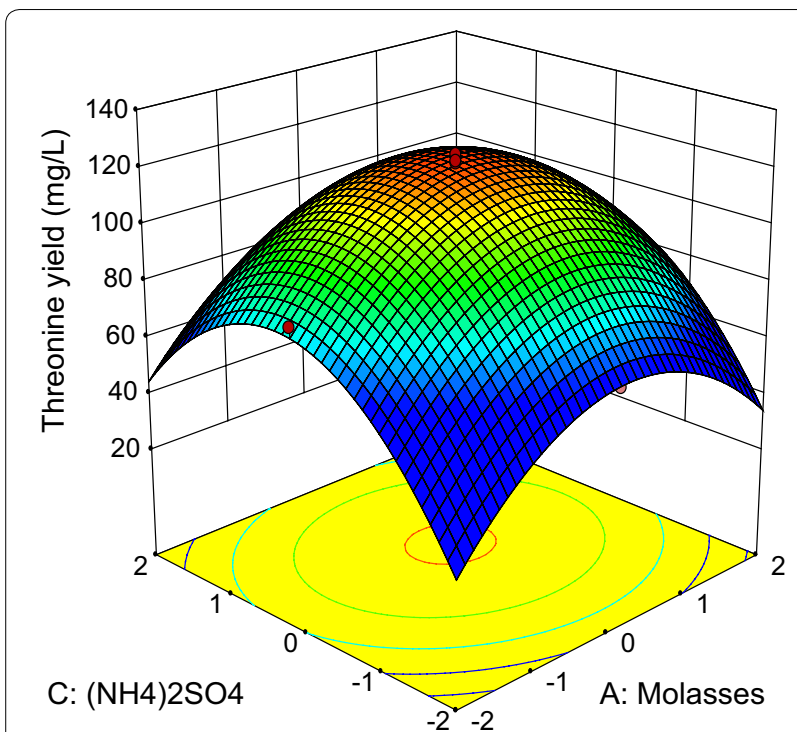

Fig. 4 Response surface of net threonine produced by P. pentosaceus $\mathrm{TL}-3$ as functions of molasses and $\left(\mathrm{NH}_{4}\right)_{2} \mathrm{SO}_{4}$

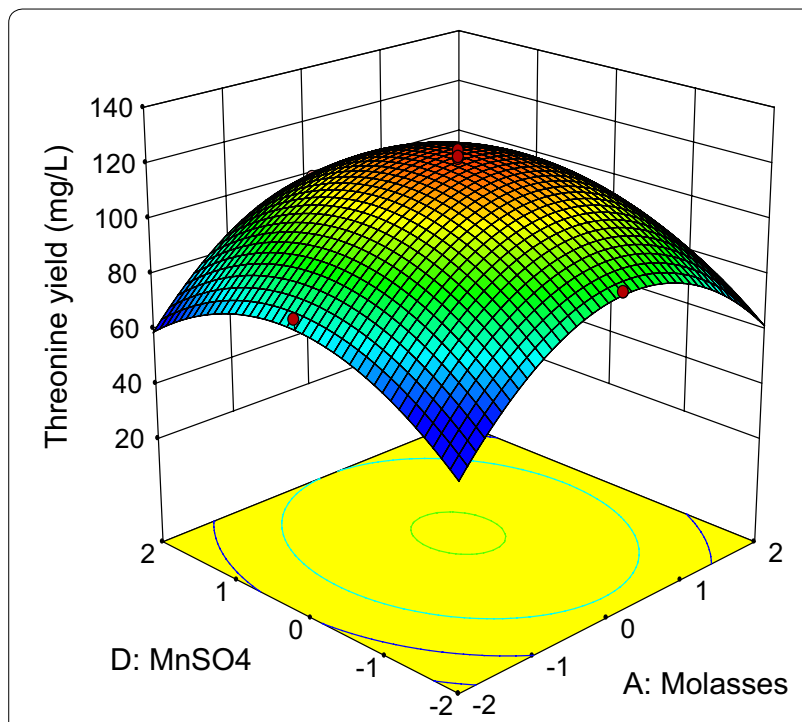

Fig. 5 Response surface of net threonine produced by P. pentosaceus $\mathrm{TL}-3$ as functions of molasses and $\mathrm{MnSO}_{4}$

PBD. Subsequently, the effects of significant variables identified in the PBD were validated and the medium formulation that showed the highest threonine production was selected for further optimization. Next, the steepest ascent method was employed to search for the vicinity of optimum operating regions for threonine production by $P$. pentosaceus TL-3. Thereafter, the optimum level of each medium component for threonine production by $P$. pentosaceus TL-3 was determined by using CCD, followed by the validation of threonine production by $P$. pentosaceus TL-3 using the optimized medium.

\section{Plackett Burman design}

PBD was used to evaluate the effects of medium components on threonine production by $P$. pentosaceus TL-3 [85]. The design of experiment and statistical analysis of data were performed by using Design Expert statistical software version 9.0.6.2 (State-Ease Inc, Minneapolis). A total of 22 medium components including 5 carbon sources (glucose, sucrose, fructose, lactose and molasses); 3 organic nitrogen sources (yeast extract, peptone and meat extract); 4 inorganic nitrogen sources (urea, $\mathrm{NH}_{4} \mathrm{NO}_{3},\left(\mathrm{NH}_{4}\right)_{2} \mathrm{SO}_{4}$ and $\left.\left(\mathrm{NH}_{4}\right)_{2} \mathrm{HC}_{6} \mathrm{H}_{5} \mathrm{O}_{7}\right) ; 8$ mineral sources $\left(\mathrm{K}_{2} \mathrm{HPO}_{4}, \mathrm{KH}_{2} \mathrm{PO}_{4}, \mathrm{NaOAc}, \mathrm{MgSO}_{4}, \mathrm{MnSO}_{4}\right.$, $\mathrm{FeSO}_{4}, \mathrm{ZnSO}_{4}$ and $\left.\mathrm{CuSO}_{4}\right) ; 1$ non-ionic surfactant (Tween 80 ) and 1 vitamin (biotin), which may have effect on amino acid production were selected by referring to the MRS medium compositions and published reports. Each of the selected medium component was assigned at 2 levels, which were high level $(+1)$ and low level $(-1)$ as shown in Table 1. A 24 experimental runs PBD was suggested by the software as presented in Table 2 . The response was expressed by the first-order model as shown in Eq. (4):

$$
\mathrm{Y}=\beta_{0}+\sum_{i=1}^{22} \beta_{\mathrm{i}} \mathrm{X}_{\mathrm{i}}
$$

where $Y$ represents the response variable, $\beta_{0}$ is the interception coefficient and $\beta_{\mathrm{i}}$ is the coefficients of the linear effects of the 22 independent variables $\left(X_{1}-X_{22}\right)$.

A validation test was subsequently conducted to verify the effect of the significant medium components identified in the PBD on threonine production by $P$. pentosaceus TL-3. A total of 7 media (Table 5) were formulated based on the ANOVA results of threonine production obtained from the PBD study (Table 3). Formulation 1 comprised all the significant medium components; Formulation 2 contained only the significant medium components with positive effect, whereas Formulation 3 was similar with Formulation 2 with addition of molasses since it was the only carbon source exerted a positive effect. In comparison, Formulation 4 was made up of all the medium components with positive effect regardless of their level of significance; Formulation 5, 6 and 7 constituted of 4 main medium components representing the carbon source, organic nitrogen source, inorganic nitrogen source and mineral source. The basal medium of Formulation 5, 6 and 7 contained molasses, $\left(\mathrm{NH}_{4}\right)_{2} \mathrm{SO}_{4}$ and $\mathrm{MnSO}_{4}$ as carbon source, inorganic nitrogen source and mineral source respectively. However, they varied in organic nitrogen source, whereby Formulation 5, 6 


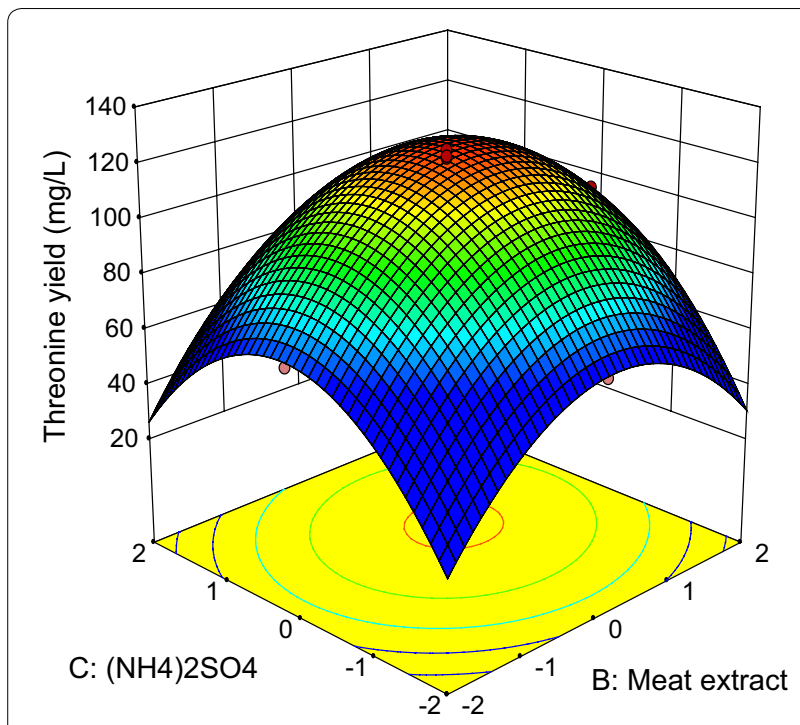

Fig. 6 Response surface of net threonine produced by P. pentosaceus TL-3 as functions of meat extract and $\left(\mathrm{NH}_{4}\right)_{2} \mathrm{SO}_{4}$

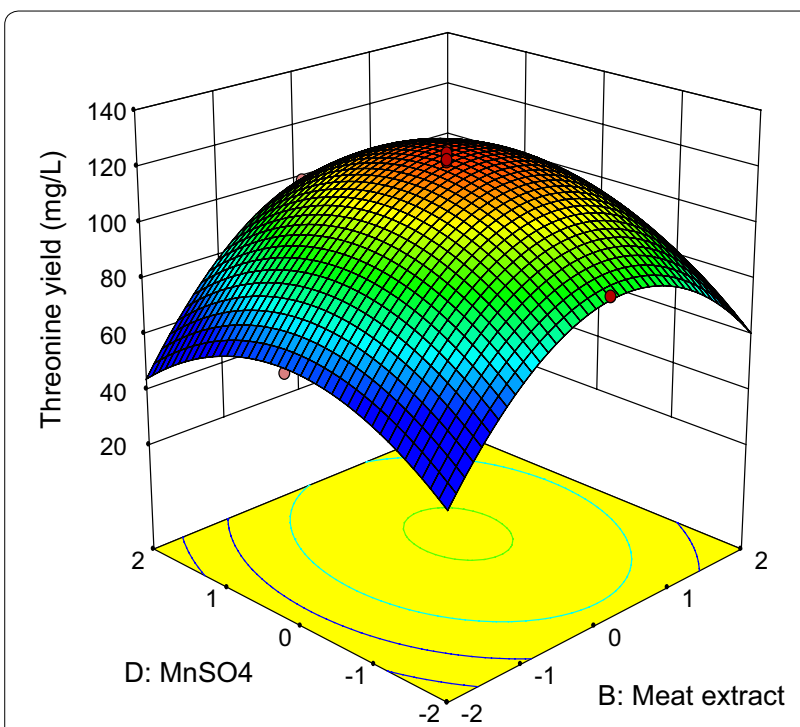

Fig. 7 Response surface of net threonine produced by P. pentosaceus $\mathrm{TL}-3$ as functions of meat extract and $\mathrm{MnSO}_{4}$

and 7 contained peptone, meat extract and yeast extract respectively.

\section{Steepest ascent method}

The steepest ascent method was used to determine optimum concentration proximity of the significant medium components for threonine production by $P$. pentosaceus TL-3. Based on the results obtained in validation test of PBD, four medium components [molasses, meat extract,
$\left(\mathrm{NH}_{4}\right)_{2} \mathrm{SO}_{4}$ and $\mathrm{MnSO}_{4}$ ] that gave the highest net threonine production were selected for further optimization. The first-order model generated by the PBD (Eq. 1) was employed to determine the direction and step length of each medium component in the steepest ascent method. The largest coefficient was used as the standard for the calculation of step length [86]. All tested medium components carried a positive sign and moved along the path of steepest ascent. The concentration of molasses, $\left(\mathrm{NH}_{4}\right)_{2} \mathrm{SO}_{4}$ and $\mathrm{MnSO}_{4}$, was increased by $5.5 \%, 17 \%$ and $34 \%$ respectively, when the concentration of meat extract was increased by $50 \%$. The steepest ascent design for threonine production by $P$. pentosaceus TL-3 is presented in Table 7. The medium that resulted the highest net threonine produced was selected for further optimization by CCD.

\section{Central composite design}

The optimum concentration of the selected medium components (molasses, meat extract, $\left(\mathrm{NH}_{4}\right)_{2} \mathrm{SO}_{4}$ and $\mathrm{MnSO}_{4}$ ) for threonine production by $P$. pentosaceus TL-3 was determined by using CCD. The design of experiment and statistical analysis of the data were performed by using Design Expert statistical software version 9.0.6.2 (State-Ease Inc, Minneapolis, MN). The concentration of each medium component was assigned to 5 levels: high level $(+1)$, low level $(-1)$, central point $(0)$ and 2 axial points $( \pm \alpha)$ as shown in Table 9. An axial distance of 2 was chosen to make the design rotatably. The CCD suggested a total of 30 experimental runs ( 16 factorial points, 8 axial points and 6 central points) as shown in Table 10. The production of threonine by $P$. pentosaceus TL-3 was expressed by the second-order model as shown in Eq. (5):

$$
Y=\beta_{0}+\sum \beta_{j} X_{j}+\sum \beta_{j^{2}} X_{j^{2}}+\sum \beta_{j k} X_{j} X_{k}
$$

where $Y$ denotes the response variable and $\beta_{0}$ is the interception coefficient, while $\beta_{\mathrm{j}}, \beta_{\mathrm{j}}^{2}$, and $\beta_{\mathrm{jk}}$ were linear, quadratic and interactive coefficient respectively.

\section{Production of threonine}

The extracellular production of threonine was conducted as described by Lim et al. [26]. A volume of $10 \%(\mathrm{v} / \mathrm{v})$ inoculum prepared as described in "Microorganism and inoculum preparation" section was inoculated into the designed media and incubated at $30{ }^{\circ} \mathrm{C}$ for $10 \mathrm{~h}$. The cultured broth was centrifuged at $10,000 \times g$ for $10 \mathrm{~min}$ at $4{ }^{\circ} \mathrm{C}$ to separate the biomass from the supernatant. The biomass was used for the determination of cell population, whereas the supernatant was used for the determination of threonine production. 


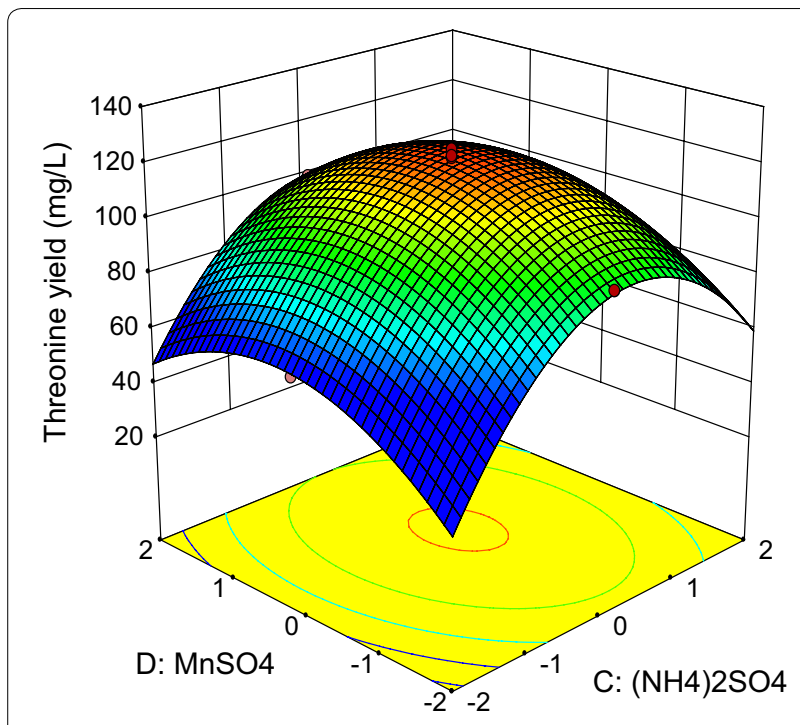

Fig. 8 Response surface of net threonine produced by $P$. pentosaceus $\mathrm{TL}-3$ as functions of $\left(\mathrm{NH}_{4}\right)_{2} \mathrm{SO}_{4}$ and $\mathrm{MnSO}_{4}$

\section{Analytical methods}

\section{Cell population determination}

The cell pellet was washed once with $0.85 \%(\mathrm{w} / \mathrm{v}) \mathrm{NaCl}$ solution, followed by a 10-fold serial dilution from $10^{0}$ to $10^{-9}$. Next, $100 \mu \mathrm{L}$ of each dilution was spread on MRS agar plate and incubated for $48 \mathrm{~h}$ at $30{ }^{\circ} \mathrm{C}$. The cell population was calculated by using the following equation:

$$
\begin{aligned}
& \text { Cell population }(\log \mathrm{CFU} / \mathrm{mL}) \\
& \quad=\log \frac{\text { Colony forming unit }}{\text { Dilution factor } \times \text { Volume of culture }(\mathrm{mL})}
\end{aligned}
$$

\section{Threonine concentration determination}

The extracellular threonine content was determined by using Agilent 1260 high performance liquid chromatograph (HPLC) (Agilent Technologies, USA) as described by Henderson et al. [17, 87]. Derivatization of amino acids were performed by using o-phthalaldehyde (OPA) and 9-fluorenylmethyl chloroformate (FMOC). The derivatized amino acids were separated on a Zorbax Eclipse Plus C18 reverse phase column $(4.6 \mathrm{~mm} \times 150 \mathrm{~mm}, 3.5 \mu \mathrm{m})$ (Agilent Technologies, USA), followed by elution with $40 \mathrm{mM}$ sodium dihydrogen phosphate monohydrate (Merck, Germany) pH 7.8 buffer and a methanol-acetonitrile-deionized water mixture (9:9:2) at a constant flow rate of $2 \mathrm{~mL} / \mathrm{min}$. The OPA, FMOC and $\mathrm{NaH}_{2} \mathrm{PO}_{4} \cdot \mathrm{H}_{2} \mathrm{O}$ were analytical grade, while the methanol and acetonitrile were HPLC grade that purchased from Merck. The eluted derivatized amino acids were detected by a fluorescence detector at the excitation/emission wavelengths of $340 / 450 \mathrm{~nm}$. The threonine concentration was quantified by referring to the calibration curve constructed by using amino acid standard (Sigma Aldrich, USA). The production of threonine was calculated by deducting the final concentration of threonine for each experimental run with their respective initial threonine concentration. All analyses were performed in triplicates.

\section{Statistical analysis}

The results were analyzed by one-way analysis of variance (ANOVA) using Statistical Analysis System (SAS 9.1, USA). Duncan's Multiple Range Test System was used to compare the significant difference between the mean at $\mathrm{p}<0.05$.

\section{Abbreviations}

LAB: lactic acid bacteria; GRAS: Generally Recognized as Safe; EMS: eosinophils myalgia syndrome; PBD: Plackett-Burman design; CCD: central composite design; $\mathrm{NADP}^{+}$: nicotinamide adenine dinucleotide phosphate; GABA: gamma-aminobutyric acid; ANOVA: analysis of variance; MRS: de Man, Rogosa and Sharpe; HPLC: high performance liquid chromatograph; OPA: o-phthalaldehyde; FMOC: 9-fluorenylmethyl chloroformate.

\section{Acknowledgements}

The authors would like to thank Ministry of Education of Malaysia for funding the research grant under Long-Term Research Grant Scheme (LRGS).

\section{Authors' contributions}

YHL, HLF, TCL, RM, RAR, ZI, YHL carried out the current study and drafted the manuscript. HLF participated in the design, conceived and coordination of this study; and helped to draft and revised the manuscript. TCL participated in the design of the study and performed the statistical analysis as well as funding acquisition. RM participated in the design of the production profile and analyses of amino acid productions. ZI contributed on the acquisition of funding and provided resources required for the completion of this study. All authors read and approved the final manuscript.

\section{Funding}

This project was supported by the Long-Term Research Scheme (LRGS) provided by the Ministry of Education Malaysia (Grant No. UPM/700-1/3/LRGS).

\section{Availability of data and materials}

The datasets used and/or analysed during this study are available from the corresponding author on reasonable request.

Ethics approval and consent to participate

Not applicable.

\section{Consent for publication}

Not applicable.

\section{Competing interests}

The authors declare that they have no competing interests.

\section{Author details}

${ }^{1}$ Institute of Bioscience, Universiti Putra Malaysia, 43400 UPM Serdang, Selangor, Malaysia. ${ }^{2}$ Department of Bioprocess Technology, Faculty of Biotechnology and Biomolecular Sciences, Universiti Putra Malaysia, 43400 UPM Serdang, Selangor, Malaysia. ${ }^{3}$ Department of Animal Science, Faculty of Agriculture, Universiti Putra Malaysia, 43400 UPM Serdang, Selangor, Malaysia. ${ }^{4}$ Institute of Tropical Agriculture and Food Security, Universiti Putra Malaysia, 43400 UPM Serdang, Selangor, Malaysia. ${ }^{5}$ Institute of Tropical Forestry and Forest Products, Universiti Putra Malaysia, 43400 UPM Serdang, Selangor, Malaysia. ${ }^{6}$ Department of Cell and Molecular Biology, Faculty of Biotechnology and Biomolecular Sciences, Universiti Putra Malaysia, 43400 UPM Serdang, Selangor, Malaysia. ${ }^{7}$ Halal Products Research Institute, Universiti Putra Malaysia, 43400 UPM Serdang, Selangor, Malaysia. 
Received: 7 April 2019 Accepted: 6 July 2019

Published online: 22 July 2019

\section{References}

1. Debabov VG. The threonine story. In: Faurie R, Thommel J, Bathe B, Debabov VG, Huebner S, Ikeda M, Kimura E, Marx A, Möckel B, Mueller U, Pfefferle W, editors. Microbial production of L-amino acids. Berlin: Springer; 2003. p. 113-36.

2. Corzo A, Kidd MT, Dozier WA III, Pharr GT, Koutsos EA. Dietary threonine needs for growth and immunity of broilers raised under different litter conditions. J Appl Poult Res. 2007;16:574-82.

3. Hermann T, Rieping M. Fermentation process for the preparation of L-threonine. United States Patent No. 6562601; 2003.

4. Święch E, Boryczka M, Taciak M, Buraczewska L. The effect of graded levels of dietary threonine on nitrogen retention and structure of the small intestine in young pigs. J Anim Feed Sci. 2011;20:350-60.

5. Xie M, Zhang L, Wen ZG, Tang J, Huang W, Hou SS. Threonine requirement of White Pekin Ducks from hatch to $21 \mathrm{~d}$ of age. Br Poult Sci. 2014;55(4):553-7.

6. Diesveld R, Tietze N, Fürst O, Reth A, Bathe B, Sahm H, Eggeling L. Activity of exporters of Escherichia coli in Corynebacterium glutamicum, and their use to increase L-threonine production. J Mol Microbiol Biotechnol. 2009;16:198-207.

7. Zhang X, Yan J, Yu L, Zhang G, Zhang Y, Chen N, Wen T. Construction of recombinant plasmids containing threonine operon and their effects on L-threonine accumulation. Acta Microbiol Sin. 2009:49(5):591-6.

8. Hartzema AG, Porta MS, Tilson HH, Milburn DS, Myers CW. Tryptophan toxicity: a pharmacoepidemiologic review of eosinophilia-myalgia syndrome. Ann Pharmacother. 1991:25(11):1259-62.

9. Mayo B, Aleksandrzak-Piekarczyk T, Fernandez M, Kowalczyk M, AlvarezMartin P, Bardowski J. Updates in the metabolism of lactic acid bacteria. In: Mozzi F, Raya RR, Vignola GM, editors. Biotechnology of lactic acid bacteria-novel applications. New Jersey: Wiley-Blackwell; 2010. p. 3-33.

10. Aro SO, Aletor VA. Proximate composition and amino acid profile of differently fermented cassava tuber wastes collected from a cassava starch producing factory in Nigeria. Livest Res Rural Dev. 2012;24(3):1-5.

11. Garault P, Letort C, Juillard V, Monnet V. Branched-chain amino acid biosynthesis is essential for optimal growth of Streptococcus thermophilus in milk. Appl Environ Microbiol. 2000;66(12):5128-33.

12. Odunfa SA, Adeniran SA, Teniola OD, Nordstrom J. Evaluation of lysine and methionine production in some Lactobacilli and yeasts from Ogi. Int J Food Microbiol. 2001;63(1):159-63.

13. Savijoki K, Ingmer H, Varmanen P. Proteolytic systems of lactic acid bacteria. Appl Microbiol Biotechnol. 2006;71:394-406.

14. Simova E, Simov Z, Beshkova D, Frengova G, Dimitrov Z, Spasov Z. Amino acid profiles of lactic acid bacteria, isolated from kefir grains and kefir starter made from them. Int J Food Microbiol. 2006;107(2):112-23.

15. Tarek M, Hesham T. Screening of potential infants' Lactobacilli isolates for amino acids production. Afr J Microbiol Res. 2010;4:226-32.

16. Zareian M, Ebrahimpour A, Bakar FA, Mohamed AKS, Forghani B, Ab-Kadir MSB, Saari N. A glutamic acid-producing lactic acid bacteria isolated from Malaysian fermented foods. Int J Mol Sci. 2012;13(5):5482-97.

17. Toe CJ, Foo HL, Loh TC, Rosfarizan M, Raha AR, Zulkifli I. Extracellular proteolytic activity and amino acid production by lactic acid bacteria Isolated from Malaysian foods. Int J Mol Sci. 2019:20(7):1777.

18. Norfarina MN, Mohd Shamzi M, Loh TC, Foo HL, Raha AR, Tan JS, Rosfarizan M. Comparative analyses on medium optimization using, response surface methodology, and artificial neural network for lysine-methionine biosynthesis by RF-1. Biotechnol \& Biotechnol Equipment. 2017;31(5):935-47.

19. Greasham RL. Media for microbial fermentations. In: Rehm HJ, Reed G, editors. Biotechnology Set. 2nd ed. Weinheim: Wiley-VCH Verlag GmbH; 1983. p. 128-39.

20. Li J, Ma C, Ma Y, Li Y, Zhou W, Xu P. Medium optimization by combination of response surface methodology and desirability function: an application in glutamine production. Appl Microbiol Biotechnol. 2007;74(3):563-71.

21. Xiao ZJ, Liu PH, Qin JY, Xu P. Statistical optimization of medium components for enhanced acetoin production from molasses and soybean meal hydrolysate. Appl Microbiol Biotechnol. 2007;74(1):61-8.
22. Altekar M, Homon CA, Kashem MA, Mason SW, Nelson RM, Patnaude LA, Yingling J, Taylor PB. Assay optimization: a statistical design of experiments approach. J Assoc Lab Autom. 2006;11(1):33-41.

23. Miller JN. Experimental design and optimization (4): Plackett-Burman designs. Anal Methods. 2013;5(8):1901-3.

24. Li H, Qiu T, Gao D, Cao Y. Medium optimization for production of gamma-aminobutyric acid by Lactobacillus brevis NCL912. Amino Acids. 2010;38(5):1439-45

25. Shi XF, Chang CY, Ma SX, Cheng YB, Zhang J, Gao Q. Efficient bioconversion of $\mathrm{L}$-glutamate to $\gamma$-aminobutyric acid by Lactobacillus brevis resting cells. J Ind Microbiol Biotechnol. 2017;44(4-5):697-704.

26. Lim YH, Foo HL, Loh TC, Rosfarizan M, Norhani A. Comparative studies of versatile extracellular proteolytic activities of lactic acid bacteria and their potential for extracellular amino acid productions as feed supplements. J Anim Sci Biotechnol. 2019;10(15):1-13.

27. Zhu LW, Wang CC, Liu RS, Li HM, Wan DJ, Tang YJ. Actinobacillus succinogenes ATCC 55618 fermentation medium optimization for the production of succinic acid by response surface methodology. J Biomed Biotechnol. 2012;2012:1-9.

28. Li Y, Liu Z, Zhao H, Xu Y, Cui F. Statistical optimization of xylanase production from new isolated Penicillium oxalicum ZH-30 in submerged fermentation. Biochem Eng J. 2007;34(1):82-6.

29. Chauhan K, Trivedi U, Patel KC. Statistical screening of medium components by Plackett-Burman design for lactic acid production by Lactobacillus sp. KCP01 using date juice. Bioresour Technol. 2007;98(1):98-103.

30. Ikeda M. Amino acid production processes. In: Faurie R, Thommel J, editors. Microbial production of L-amino acids. Berlin: Springer; 2003. p. 1-35.

31. Hagino H, Nakayama K. L-Tryptophan production by analog-resistant mutants derived from a phenylalanine and tyrosine double auxotroph of Corynebacterium glutamicum. Agric Biol Chem. 1975;39(2):343-9.

32. Frape D. Equine nutrition and feeding. Hoboken: Blackwell Publishing: 2008.

33. Kroner Z. Vitamins and minerals. Santa Barbara: ABC-CLIO Greenwood; 2011.

34. Faehnle CR, Le Coq J, Liu X, Viola RE. Examination of key intermediates in the catalytic cycle of aspartate- $\beta$-semialdehyde dehydrogenase from a Gram-positive infectious bacteria. J Biol Chem. 2006;281 (41):31031-40.

35. Cahyanto MN, Kawasaki H, Nagashio M, Fujiyama K, Seki T. Regulation of aspartokinase, aspartate semialdehyde dehydrogenase, dihydrodipicolinate synthase and dihydrodipicolinate reductase in Lactobacillus plantarum. Microbiology. 2006;152:105-12.

36. Matthews BF, Widholm JM. Regulation of lysine and threonine synthesis in carrot cell suspension cultures and whole carrot roots. Planta. 1978;141(3):315-21.

37. György P. The history of vitamin B6. Introductory remarks. In: Harris RS, Wool IG, Loraine JA, Marrian GF, Thimann KV, editors. Vitamins and hormones, vol. 22. New York: Academic Press Inc.; 1964. p. 361-5.

38. McDowell LR. Vitamins in animal and human nutrition. 2nd ed. Ames: lowa State University Press; 2000.

39. Malumbres M, Mateos LM, Lumbreras MA, Guerrero C, Martin JF. Analysis and expression of the thrC gene of Brevibacterium lactofermentum and characterization of the encoded threonine synthase. Appl Environ Microbiol. 1994;60(7):2209-19.

40. Lee K, Lee J, Kim YH, Moon SH, Park YH. Unique properties of four Lactobacilli in amino acid production and symbiotic mixed culture for lactic acid biosynthesis. Curr Microbiol. 2001;43(6):383-90.

41. Faghfuri E, Fooladi J, Moosavi-Nejad SZ. L-tryptophan production by whole cells of Escherichia coli based on Iranian sugar beet molasses. Jundishapur J Microbiol. 2013;6(4):1-5.

42. Wang J, Cheng LK, Chen N. High-level production of L-threonine by recombinant Escherichia coli with combined feeding strategies. Biotechnol Biotechnol Equip. 2014;28(3):495-501.

43. Rieping M, Hermann T. L-Threonine. In: Wendisch VF, editor. Amino acid biosynthesis-pathways, regulation and metabolic engineering. Berlin: Springer; 2006. p. 71-92.

44. Davati N, Hamidi Esfahani Z, Shojaosadati SA. Optimization of medium composition for microbial production of glutamic acid from Date fruit wastes using fractional factorial method. Iran J Food Sci Technol. 2010;7(25):61-7.

45. Masuda M, Takamatsu S, Nishimura N, Komatsubara S, Tosa T. Improvement of nitrogen supply for L-threonine production by a 
recombinant strain of Serratia marcescens. Appl Biochem Biotechnol. 1992;37(3):255-65.

46. Chen N, Huang J, Feng ZB, Yu L, Xu QY, Wen TY. Optimization of fermentation conditions for the biosynthesis of L-threonine by Escherichia coli. Appl Biochem Biotechnol. 2009;158(3):595-604.

47. Lee MH, Lee HW, Park JH, Ahn JO, Jung JK, Hwang YI. Improved L-threonine production of Escherichia coli mutant by optimization of culture conditions. J Biosci Bioeng. 2006;101(2):127-30.

48. Okamoto K, Ikeda M. Development of an industrially stable process for L-threonine fermentation by an L-methionine-auxotrophic mutant of Escherichia coli. J Biosci Bioeng. 2000;89(1):87-9.

49. Miyajima R, Shiio I. Regulation of aspartate family amino acid biosynthesis in Brevibacterium flavum V. Properties of homoserine kinase. J Biochem. 1972;71(2):219-26.

50. Neysens P, Messens W, De Vuyst L. Effect of sodium chloride on growth and bacteriocin production by Lactobacillus amylovorus DCE 471. Int J Food Microbiol. 2003;88(1):29-39.

51. Kumar M, Jain AK, Ghosh M, Ganguli A. Statistical optimization of physical parameters for enhanced bacteriocin production by L. casei. Biotechnol Bioprocess Eng. 2012;17:606-16.

52. Verellen TL, Bruggeman G, Van Reenen CA, Dicks LM, Vandamme EJ. Fermentation optimization of plantaricin 423 , a bacteriocin produced by Lactobacillus plantarum 423. J Ferment Bioeng. 1998;86(2):174-9.

53. Wright JK, Feldman J, Takahashi M. Cobalt (III) affinity-labeled aspartokinase. Formation of substrate and inhibitor adducts. Biochemistry. 1976;15(17):3704-10.

54. Burr B, Walker J, Truffa-Bachi P, Cohen GN. Homoserine kinase from Escherichia coli K12. Eur J Biochem. 1976;62(3):519-26.

55. Theze J, Kleidman L, Saint Girons I. Homoserine kinase from Escherichia coli K-12: properties, inhibition by L-threonine, and regulation of biosynthesis. J Bacteriol. 1974:118(2):577-81.

56. Kiefer P, Heinzle E, Wittmann C. Influence of glucose, fructose and sucrose as carbon sources on kinetics and stoichiometry of lysine production by Corynebacterium glutamicum. J Ind Microbiol Biotechnol. 2002:28(6):338-43.

57. Momose H, Takagi T. Glutamic acid production in biotin-rich media by temperature-sensitive mutants of Brevibacterium lactofermentum, a novel fermentation process. Agric Biol Chem. 1978;42(10):1911-7.

58. Todorov SD, Dicks LM. Bacteriocin production by Lactobacillus pentosus ST712BZ isolated from boza. Braz J Microbiol. 2007;38(1):166-72.

59. Saraniya A, Jeevaratnam K. Optimization of nutritional and non-nutritional factors involved for production of antimicrobial compounds from Lactobacillus pentosus SJ65 using response surface methodology. Braz J Microbiol. 2014;45(1):81-8.

60. Nampoothiri KM, Pandey A. Effect of different carbon sources on growth and glutamic acid fermentation by Brevibacterium sp. J Basic Microbiol. 1995:35(4):249-54.

61. Saeed AH, Salam Al. Current limitations and challenges with lactic acid bacteria: a review. Food Nutr Sci. 2013:4:73-87.

62. Pirie P, Naeimpoor F, Hejazi P. A microcosm study on P-nitrophenol biodegradation in soil slurry by Alcaligenes faecalis: Plackett-Burman design. Iran J Chem Eng. 2011;8(2):57-68.

63. De Carvalho AAT, Mantovani HC, Paiva AD, De Melo MR. The effect of carbon and nitrogen sources on bovicin HC5 production by Streptococcus bovis HC5. J Appl Microbiol. 2009;107(1):339-47.

64. Mohamed IA, Loh TC, Foo HL, Lau WH, Awis QS. Biodegradation of palm kernel cake by cellulolytic and hemicellulolytic bacterial cultures through solid state fermentation. Sci World J. 2014;2014:1-8.

65. Oh H, Wee YJ, Yun JS, Han SH, Jung S, Ryu HW. Lactic acid production from agricultural resources as cheap raw materials. Bioresour Technol. 2005;96(13):1492-8.

66. Safari R, Motamedzadegan A, Ovissipour M, Regenstein JM, Gildberg A, Rasco B. Use of hydrolysates from yellowfin tuna (Thunnus albacares) heads as a complex nitrogen source for lactic acid bacteria. Food and Bioprocess Technol. 2012;5(1):73-9.

67. Rodrigues L, Teixeira J, Oliveira R, Van Der Mei HC. Response surface optimization of the medium components for the production of biosurfactants by probiotic bacteria. Process Biochem. 2006;41(1):1-10.

68. Kadam SR, Patil SS, Bastawde KB, Khire JM, Gokhale DV. Strain improvement of Lactobacillus delbrueckii NCIM 2365 for lactic acid production. Process Biochem. 2006:41(1):120-6.
69. Hutkins RW. Microbiology and technology of fermented foods, vol. 22. lowa: Blackwell Publishing; 2008.

70. Naveena BJ, Altaf M, Bhadriah K, Reddy G. Selection of medium components by Plackett-Burman design for production of $L(+)$ lactic acid by Lactobacillus amylophilus GV6 in SSF using wheat bran. Bioresour Technol. 2005;96(4):485-90.

71. De Carvalho IPC, Detmann E, Mantovani HC, Paulino MF, Valadares Filho SDC, Costa VAC, Gomes DI. Growth and antimicrobial activity of lactic acid bacteria from rumen fluid according to energy or nitrogen source. $R$ Bras Zootec. 2011;40(6):1260-5.

72. Grobben GJ, Boels IC, Sikkema J, Smith MR, De Bont JA. Influence of ions on growth and production of exopolysaccharides by Lactobacillus delbrueckii subsp. bulgaricus NCFB 2772. J Dairy Res. 2000;67(1):131-5.

73. Mahrous H, Mohamed A, El-Mongy MA, El-Batal A, Hamza H. Study bacteriocin production and optimization using new isolates of Lactobacillus spp. isolated from some dairy products under different culture conditions. Food Nutr Sci. 2013;4:342-56.

74. Thu TV, Foo HL, Loh TC, Bejo MH. Inhibitory activity and organic acid concentrations of metabolite combinations produced by various strains of Lactobacillus plantarum. Afr J Biotechnol. 2011;10(8):1359-63.

75. Tomas JMS, Bru E, Nader-Macia ME. Different combinations of salts affect the growth and bacteriocin production by Lactobacillus salivarius CRL 1328. J Chem Technol Biotechnol. 2010;85:91-9.

76. Foucaud C, Francois A, Richard J. Development of a chemically defined medium for the growth of Leuconostoc mesenteroides. Appl Environ Microbiol. 1997;63(1):301-4.

77. Oh S, Rheem S, Sim J, Kim S, Baek Y. Optimizing conditions for the growth of Lactobacillus casei YIT 9018 in tryptone-yeast extract-glucose medium by using response surface methodology. Appl Environ Microbiol. 1995;61(11):3809-14.

78. Jenkins JK, Courtney PD. Lactobacillus growth and membrane composition in the presence of linoleic or conjugated linoleic acid. Can J Microbiol. 2003:49(1):51-7.

79. Li JY, Zhang LW, Du M, Han X, Yi HX, Guo CF, Zhang YC, Luo X, Zhang YH, Shan YJ, Hou AJ. Effect of tween series on growth and cis-9, trans-11 conjugated linoleic acid production of Lactobacillus acidophilus F0221 in the presence of bile salts. Int J Mol Sci. 2011;12(12):9138-54.

80. Tripuraneni S. Effect of nutrient supplements on cucumber fermentation by lactic acid bacteria. M. Sc. thesis. Fayetteville: University Of Arkansas; 2011

81. Rosen K. Production of baker's yeast. In: Berry DR, Russell I, Steward GC, editors. Yeast Biotechnology. London: Unwin Hyman Ltd.; 2012. p. 471-500.

82. Lim YS. Isolation of bacteriocinogenic lactic acid bacteria and purification of selected bacteriocins from traditional fermented foods. M. Sc. thesis. Serdang: Universiti Putra Malaysia; 2003.

83. Kareem KY, Foo HL, Loh TC, Ooi MF, Asmara SA. Inhibitory activity of postbiotic produced by strains of Lactobacillus plantarum using reconstituted media supplemented with inulin. Gut Pathog. 2014;6(23):1-7.

84. Ooi MF, Nurzafirah M, Foo HL, Loh TC, Rosfarizan M, Raha AR, Arbakariya A Effects of carbon and nitrogen sources on bacteriocin-inhibitory activity of postbiotic metabolites produced by Lactobacillus plantarum I-UL4. Malays J Microbiol. 2015:11(2):176-84.

85. Azin A, Rosfarizan M, Raha AR, Rosli MI, Farideh N, Tan JS, Sahar A. Cyclodextrin glycosyltransferase biosynthesis improvement by recombinant Lactococcus lactis NZ: NSP: CGT: medium formulation and culture condition optimization. Biotechnol Biotechnol Equip. 2015;29(3):555-63.

86. Gao X, Qiao SY, Lu WQ. Determination of an economical medium for growth of Lactobacillus fermentum using response surface methodology. Lett Appl Microbiol. 2009;49(5):556-61.

87. Henderson JW, Ricker RD, Cliff WI. Rapid, accurate, sensitive and reproducible HPLC analysis of amino acids. Agilent Technologies, Appl. note: 5980-1193; 2000.

\section{Publisher's Note}

Springer Nature remains neutral with regard to jurisdictional claims in published maps and institutional affiliations. 